


\section{FIELD PERFORMANCE OF RESIDENTIAL REFRIGERATORS AND COMBINATION REFRIGERATOR-FREEZERS}

Yui-May L. Chang and Richard A. Grot

Building Thermal \& Service Systems Division Center for Building Technology National Engineering Laboratory National Bureau of Standards

Washington, D.C. 20234

July 1979

U.S. DEPARTMENT OF COMMERCE, Juanita M. Kreps, Secretary Luther H. Hodges, Jr., Under Secretary Jordan J. Baruch, Assistant Secretary for Science and Technology NATIONAL BUREAU OF STANDARDS, Ernest Ambler, Director 



\title{
FIELD PERFORMANCE OF RESIDENTIAL REFRIGERATORS AND COMBINATION REFRIGERATOR-FREEZERS
}

\author{
Yui-May L. Chang and Richard A. Grot
}

\begin{abstract}
$\underline{\text { ABSTRACT }}$
Evaluation of the performance of household refrigerators and combination refrigerator-freezers was undertaken in a field experiment to determine the effect of room environment and occupant-usage habits on energy consumption of these appliances. This report presents the results of such an experiment on ten townhouses at Twin Rivers, N.J. One-door manual defrost and two-door frost-free models of various sizes were studied. Energy consumption, kitchen temperature, refrigerator temperature and door openings were measured for each model by data acquisition systems located in the townhouse basements. Both daily and hourly averages and variations about the average for each variable were calculated in order to determine the occupant-usage patterns.
\end{abstract}

Statistical techniques were utilized to obtain the effect of parameters on energy consumption of these appliances by linear regression of both one- and two-parameter models.

It was found that for a given model the temperature difference between the kitchen and the refrigerator (either main or freezer section) had the most effect on energy consumption, with a lesser, though still important, contribution from the door openings.

In addition, the normalized energy consumption of each model, in different combinations of variables, was calculated from its regression coefficients and the overall average values of parameters from measurements. The results of these normalized values turned out to be within $5 \%$. Therefore, their mean values could be considered as the typical energy consumption for each refrigerator or combination, under usage conditions.

The linear relationship among the combination refrigerator-freezers according to their physical sizes indicated an increase of about $0.55 \mathrm{kWh}$ per day for each additional cubic foot increase in volume. Energy conservation by using a manual-defrost refrigerator was predicted at approximately $40 \%$ of that of a frost-free model.

Key Words: Combination refrigerator-freezer field data; daily load profiles; energy consumption; field measurements; hourly load profiles; refrigerator field data; usage profiles. 

TABLE OF CONTENTS

$\underline{\text { Page }}$

ABSTRACT . . . . . . . . . . . . . . . . . .

LIST OF TABLES . . . . . . . . . . . . . . . . . vi vi

LIST OF FIGURES . . . . . . . . . . . . . . . . v vii

1. INTRODUCTION . . . . . . . . . . . . . . . . 1

2. GRAPHICAL AND ANALYTICAL REPRESENTATION OF MEASUREMENTS • • • 3

2.1 Analysis of Hourly Data. . . . . . . . . . . 3

2.2 Analysis of Daily Performance........... . . 4

2.3 Analysis of the Parameter that Affect Refrigerator

3. DISCUSSION OF RESULTS ............... 8

4. CONCLUSION. . . . . . . . . . . . . 10

5. TABLES AND FIGURES . . . . . . . . . . . . . . . 11

REFERENCES •. • . . . . . . . . . . . . . . . 39 


\section{LIST OF TABLES}

(See Section 5)

Table 1. Refrigerator physical characteristics.

Table 2. Occupant and townhouse characteristics.

Table 3. Summary of average hourly energy and door openings of the refrigerator in each townhouse.

Table 4. Daily refrigerator performance.

Table 5. Coefficients of linear regression performance equation $E=\alpha_{0}+\alpha_{1} X$.

Table 6. Coefficients of multiple regression performance equation $E=\beta_{0}+\beta_{1} X+\beta_{2} X^{2}$.

Table 7. Overall values of the refrigerators.

Table 8. Normalized energy consumption of the refrigerators.

Table 9. Parameters for least-squares fit of refrigerator energy consumption versus their sizes (see Figure 29). 


\section{LIST OF FIGURES \\ (See Section 5)}

Figure 1. Schematic of refrigerator instrumentation.

Figure 2. Refrigerator hourly energy consumption, townhouse 非8

Figure 3. Hourly main-section average temperature, townhouse 非8

Figure 4. Hourly freezer average temperature, townhouse 非.

Figure 5. Hourly main-section door-opening time, townhouse 非8.

Figure 6. Hourly number of main-section door openings, townhouse 非.

Figure 7. Hourly number of freezer door openings, townhouse 非.

Figure 8. Hourly freezer door-opening time, townhouse 非.

Figure 9. Hourly average kitchen air temperature, townhouse 非8

Figure 10. Average profile of hourly energy consumption of refrigerator for townhouse 非8.

Figure 11. Average hourly profile for number of door openings of main section for refrigerator in townhouse $\equiv^{8} 8$.

Figure 12. Average hourly profile for number of door openings of freezer section of refrigerator in townhouse 非.

Figure 13. Frequency plots of energy consumption of refrigerator in townhouse 非--hours 1 to 6 .

Figure 14. Frequency plots of energy consumption of refrigerator in townhouse 非8--hours 7 to 12 .

Figure 15. Frequency plots of energy consumption of refrigerator in townhouse 非--hours 13 to 18 .

Figure 16. Frequency plots of energy consumption of refrigerator in townhouse 非--hours 19 to 24.

Figure 17. Plot of daily energy usage for refrigerator of townhouse 非8.

Figure 18. Frequency plot of daily energy usage for refrigerator of townhouse 非8.

Figure 19. Plot of daily energy consumption and differential temperature versus days for refrigerator of townhouse 非. 


\section{LIST OF FIGURES (Continued)}

Figure 20. Plot of daily energy consumption and differential temperature versus days for refrigerator of townhouse $\$$ 非

Figure 21. P1ots of daily energy consumption versus main-section differential temperature for refrigerator in townhouse 非8.

Figure 22. Plots showing lack of correlation between refrigerator energy consumption and main-section differential temperature for townhouses 非 4 and 非 9 .

Figure 23. Plots showing differential in correlation in energy consumption and differential temeprature of freezer section for townhouses $\#^{4} 4$ and $\$$ 非.

Figure 24. Plots of energy consumption versus differential temperature of main section for refrigerator in townhouses 非 1 and 非2.

Figure 25. Plots of energy consumption versus differential temperature of freezer section for refrigerator in townhouses $\#_{1} 1$ and 非2.

Figure 26. Plots of daily average differential temperature of main section versus days for refrigerator in townhouse 非

Figure 27. Plots of daily average differential temperature of freezer section versus days for refrigerator in townhouse 非 8 .

Figure 28. Plots of actual and predicted daily refrigerator energy consumption for townhouse 非8.

Figure 29. Energy consumption of household refrigerator versus refrigerator size. 


\section{FIELD PERFORMANCE OF RESIDENTIAL REFRIGERATORS AND COMBINATION REFRIGERATOR-FREEZERS}

Yui-May L. Chang and Richard A. Grot

\section{INTRODUCTION}

A field experiment* was undertaken in ten townhouses at Twin Rivers, N.J. to determine the occupant-controlled parameters which can affect the energy consumption of a household refrigerator** and to assist in a realistic appliance labeling program for evaluation of household refrigerators.

The site of Twin Rivers, N.J. was selected due to the previous extensive investigations on energy usage at that site by researchers at Princeton University $[1,2]$. The ten townhouses in this study were selected on the basis of their previous energy usage data. The object was to obtain, in a small sample, a distribution which reflected the energy usage of the population of Twin Rivers. The refrigerators studied were those already in the townhouses, either supplied by the developer or purchased separately by the occupants. The refrigerators in these townhouses were a one-door manual defrost and nine two-door frost-free models of various sizes, including one side-by-side model. The physical characteristics of the refrigerators in each town-house are given in Table 1 . The occupants were mostly typical families containing two adults and one to three children, ages from 1 to 15 years old. A summary of occupants in each townhouse is given in Table 2 .

Instrumentation was installed in each townhouse so that the energy usage of the refrigerator, the kitchen temperature, the refrigerator main-section temperature, the refrigerator freezer-section temperature, the number and duration of openings of the main section door, and the number and duration of openings of the freezer section door were recorded. Figure 1 is a schematic of the instrumentation. After the completion of instrumentation, data collection was begun in April 1976. The electric energy use of the refrigerator was measured by installing an electric meter modified so that a pulse was generated for each 1.8 watt-hours of electricity. The pulses from the electric meter were summed by a specially designed electronic counter which produced an analogue signal proportional to the total number of pulses. The opening

*This research was initially sponsored by the Energy Appliance Labeling Program of the Center for Consumer Products Technology of the National Bureau of Standards through an interagency agreement with the Federal Energy Administration.

$* *$ Refrigerator, as used in this report, refers to refrigerators as well as combination refrigerator-freezer. 
of the main section and freezer section doors were determined by placing small magnets and miniature magnetic reed switches on the door and refrigerator so that each time the door was opened or closed the magnetic reed switch would open or close. These signals were fed into an encoder card which produced an analogue signal from which the status of the door positions could be determined (i.e., whether the door was open or closed). The computer analysis determined the number and duration of door openings.

The encoder also generated a parity signal which changed state whenever the status of the encoded events changed. This means, for example, that when the refrigerator door was opened from closed position, or closed from the open position. The scan control card would generate a pulse which would in turn cause a scan of the data acquisition. From these event scans, the number and duration of each door opening could be determined. The temperatures in the kitchen and refrigerator, both main and freezer sections were measured with T-type thermocouples. The kitchen temperature thermocouple was located above the kitchen sink. The refrigerator main section temperature thermocouple was attached to a center shelf at the rear of the refrigerator. The thermocouple in the freezer section was located at the rear of the freezer section. Since the refrigerators were in use by the occupants, these locations were dictated by the circumstances. It would have been impossible to locate these thermocouples according to the standard test procedures by AHAM and ASHRAE $[3,4]$.

The instrumentation was installed so that one data acquisition system would monitor a pair of townhouses. Townhouses 非 1 and $\# 2$ shared the same data acquisition system; likewise, townhouses 非 and 非, . . . etc. For each pair of townhouses, the data acquisition system would scan and record measurements of the HVAC system, appliances and room environment periodically once every five minutes on a seven-track incremental magnetic tape recorder. In addition, it also recorded the event actuated scans caused by the opening and closing of the refrigerator doors. It took about six seconds to scan all channels of data. There are approximately 4500 scans on each tape, which is equivalent to seven days of data. The tapes were changed once a week and shipped to the National Bureau of Standards (NBS) by researchers at Princeton University, who also monitored the operation of the equipment.

The five-minute data were reduced on either the CBT minicomputer or the NBS central computer facility into daily and hourly data files, which were printed and stored on mass storage files for further analysis. The hourly data of all measurements were analyzed to obtain average hourly profiles by averaging measured values during each hour over a period of certain days. As for refrigerator door openings, on ly daily usage profiles were reduced from data, since hourly measurements were immaterial. The graphs presented in the report include actual measurements for four-day periods. From the graphical presentation of the four-day plots of internal temperature, the defrost cycle of each refrigerator can be observed. 
On the daily data summaries, statistical analyses were performed to obtain the variations from the average values and to determine the effect of usage parameters on energy consumption. According to these field measurements under actual usage conditions, the average daily energy consumption of various refrigerators was found to depend mainly on the size of the refrigerator, as expected. For a given refrigerator, the temperature difference between the kitchen and the refrigerator influenced the daily energy consumption of the refrigerator more than did the number or duration of the door openings. The average daily number of door openings for all refrigerators was found to be 48 for the main section and 10 for the freezer section. It was also interesting to learn that the average length of time per door opening for the two sections of these refrigerators turned out to be nearly the same, 21 seconds for the main section and 20 seconds for the freezer section. For all refrigerators, the average values of temperature differences between kithcen and the refrigerator, were calculated to be $\overline{\Delta \mathrm{T}}_{\mathrm{M}}=42^{\circ} \mathrm{F}$ for the main section and $\overline{\Delta \mathrm{T}}_{\mathrm{F}}=73.5^{\circ} \mathrm{F}$, for the freezer section, with kitchens at an average temperature of $78.4^{\circ} \mathrm{F}$. In order to study relationships among energy consumption, differential temperature between kitchen and refrigerators, and door openings, the leastsquares estimation of linear regression with both single and multiple variant were used.

Simple performance equations (equations 1 and 2 in section 2.3) of the mathematical model for energy usage and its dependent variables were employed. From these equations and their calculated coefficients, the predicted value and the actual data value were plotted together to show their differences for each refrigerator. The energy consumptions of refrigerators of different sizes were compared by using the overall average values of temperature difference between kitchen and refrigerators, $\overline{\Delta T}_{M}$ and $\overline{\Delta T}_{F}$, and door openings.

\section{GRAPHICAL AND ANALYTICAL REPRESENTATION OF MEASUREMENTS}

\subsection{ANALYSIS OF HOURLY DATA}

The energy consumption and the usage pattern of the refrigerator in each household are presented as averages for each hour. Refrigerator in townhouse $\beta^{8}$ is one of the six refrigerators for which a complete set of data is available and has been arbitrarily selected for presentation. The actual hourly energy consumption and temperatures of this refrigerator for a period of four days are shown in Figures 2, 3 and 4. From Figures 3 and 4, both main-section temperature and freezersection temperature can be observed to have peaks at the same time. The refrigerator is controlled in an on-off manner by a single thermostatic switch, and the temperature controls of both sections depend on their control knobs as well as a damper to limit air flow between them. Time intervals between peaks in these two figures indicate the period of defrost cycles because, at the beginning of each defrost cycle, electric heat is applied to its evaporator to melt the frost [5]. 
These two figures also show that this frost-free refrigerator has its defrost cycle occurring approximately every six hours. By studying all three graphs, Figures 2, 3, and 4, it could be seen that the hourly energy usage increases after the refrigerator self-defrosts, as the refrigerator temperature has to be reduced immediately.

Furthermore, the number and duration of door openings of the refrigerator, shown in Figure 5-8, change the refrigerator temperature patterns and therefore affect the energy usage indirectly. The periods of door openings relate directly to the number of door opening. It can also be noticed that the door openings are either zero or a very small number from midnight to $6: 00 \mathrm{am}$., and the refrigerator's internal temperature remains pretty much the same, except when the defrost cycle comes on. Therefore, the hourly energy consumption at night is usually lower than at any time of the day. This is also due to the fact that the kitchen temperature is always fairly low at night, as shown in Figure 9.

Figure 10 is an average profile of energy consumption for each hour of the day, from days 96 to 180, of the refrigerator in townhouse 非. For Figures 10, 11 and 12 the solid area is the average energy used, and the dotted profile gives two standard deviations from the average.

In comparing Figures 2 and 10, the measurements of hourly energy consumption of the refrigerator for days 176-179 and the average hourly energy consumption profile for days 96-180 do not show much similarity. In fact, Figure 2 shows a slightly higher energy usage on those four days than the average hourly energy usage given in Figure 10 and Table 3. This might be due to the surprisingly high temperature in the kitchen on those four days as shown in Figure 9. Figure 9 indicates the kitchen temperatures from measurements are much higher than the daily average value of $77.6^{\circ} \mathrm{F}$, given in Table 4 .

Figure 10 shows that slightly more energy is used during lunch time and dinner time, when refrigerator doors are opened more frequently, as indicated in Figures 11 and 12. The actual variation of refrigerator energy used in townhouse $\$$ 淁 8 for each hour of the day is shown in the set of 24-hour frequency plots (Figures 13-16). Table 3 is a summary of these variations for each hour of the day in average energy consumption and door openings of all ten townhouses.

\subsection{ANALYSIS OF THE DAILY PERFORMANCE}

When a refrigerator is being operated normally, its daily energy usage does not vary greatly; however, those variations which do occur should indicate the effect of such parameters as kitchen temperature and door openings on the energy consumption of the refrigerator. Figure 17 is a plot of the daily energy consumption of the refrigerator of townhouse \#8. The frequency plot in Figure 18 shows the energy usage of this refrigerator ranged from $4 \mathrm{kWh}$ to $8 \mathrm{kWh}$ per day, with a mean 
of $6.45 \mathrm{kWh}$ per day. A summary of the daily performance of the refrigerators in these ten townhouses is given in Table 4. By referring to Tables 1 and 4, the dependence of the refrigerator average daily energy consumption on its physical size can be noted. The values vary from $2.30 \mathrm{kWh}$ per day for the refrigerator in townhouse 非 (an $11.5 \mathrm{ft}^{3}$ one-door manual-defrost model) to $8.33 \mathrm{kWh}$ per day for the refrigerator in townhouse 非10 (a $19.0 \mathrm{ft}^{3}$ two-door side-by-side self-defrosted mode1). Note that even though the data days were different, the comparisons are still valid, since the average kitchen temperature, $\mathrm{T}_{\mathrm{K}}$, remained pretty much the same for each particular period of time, except for townhouse 非3.

For those refrigerators with the same physical characteristics as shown in Table 1 (e.g., in townhouses 非 7 and 非 8 ) the temperature difference between kitchen and refrigerator dominates their energy usage, with small effects due to the door openings. Table 4 indicates that the differential temperature between kitchen and freezer in townhouse 非, $72.1^{\circ} \mathrm{F}$, was much higher than in townhouse $k^{7}, 65.6^{\circ} \mathrm{F}$, while their differential temperatures between kitchen and main section were kept approximately the same, $44.2^{\circ} \mathrm{F}$ and $44.7^{\circ} \mathrm{F}$, respectively. This factor could explain why the refrigerator in townhouse 非 8 has a higher energy

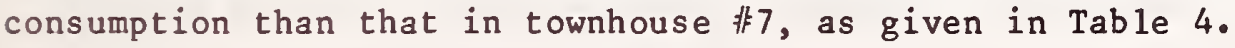

By sketching the refrigerator daily energy usage with temperature difference between kitchen and freezer of the refrigerator in townhouse 非, given in Figure 19, it can be noticed that the two curves follow a similar pattern and thus are related. Figure 20 shows the same comparisons for townhouse 非7. Comparing Figure 19 with Figure 20, it is obvious that the average daily energy consumption of the refrigerator in townhouse 非 8 is higher than that of townhouse 非 7 . The refrigerator door openings also affect the energy usage of the refrigerator, as shown in Table 4.

\subsection{ANALYSIS OF THE PARAMETERS THAT AFFECT REFRIGERATOR ENERGY CONSUMPTION}

An attempt was made to obtain the effect of various parameters on energy consumption of the refrigerators. For each townhouse, major emphasis was placed on two parameters: (a) the temperature difference between the kitchen and the refrigerator, and (b) the number and duration of its door openings.

Figure 21 shows the daily energy consumption, $E$, versus temperature difference between kitchen and main section, $\Delta \mathrm{T}_{\mathrm{M}}$, of the refrigerator in townhouse 非. The mean value of $E$ is also given as $6.45 \mathrm{kWh}$ with standard deviation equaled to $0.55 \mathrm{kWh}$, as shown in Table 4 . By using the least-squares linear regression technique, the one-parameter model of these variables is given by

$$
E=\alpha_{0}+\alpha_{1}\left(\Delta T_{M}\right),
$$


where $\mathrm{E}$ is the daily energy consumption in $\mathrm{kWh}$, and $\Delta \mathrm{T}_{\mathrm{M}}$ is the temperature difference between kitchen and main section of the refrigerator in degrees $F$. The straight line is presented on the same graph and the coefficient of equation 1 was calculated to be $\alpha_{0}=1.56$ and $\alpha_{1}=0.11$.

In equation $1, \alpha_{1}$ could be interpreted as the energy consumed per degree $F$ of temperature difference. Non-zero $\alpha_{0}$ of equation 1 indicated that the linear relationship is applicable over a limited range and also that other independent variables should be considered for analysis. The correlation coefficient, $R^{2}$, and the standard deviation of the linear regression, $\sigma_{\varepsilon}$, were obtained as 0.69 and 0.28 , respectively. The percentage gained in precision for linear regression, by reducing the standard deviation from 0.55 to 0.28 , is 50 percent.

However, $\mathrm{R}^{2}$ of 0.69 means a better model could be adopted by the method of multiple regression to include more independent variables. Table 5 gives the coefficients $\alpha_{0}$ and $\alpha_{1}$ of equation 1 together with the correlation coefficient $R^{2}$ and standard deviation $\sigma_{\varepsilon}$ for the following variables taken as independently as listed below as determined by the measurements on the refrigerator in each townhouse:

- $\Delta \mathrm{T}_{\mathrm{M}}$, temperature difference between kitchen and main section

- $\Delta \mathrm{T}_{\mathrm{F}}$, temperature difference between kitchen and freezer section

- $\mathrm{ND}_{\mathrm{M}}$, number of door openings of main section

- $\mathrm{ND}_{\mathrm{F}}$, number of door opening of freezer section

- $t D_{M}$, duration of door openings of main section

- $t D_{F}$, duration of door openings of freezer section.

From the statistical point of view, the correlation coefficient $\mathrm{R}^{2}$ is a measure of linear dependence of a dependent variable to the independent variables from the linear equation. Whenever $R^{2}$ is extremely smal1, they are linearly uncorrelated. The results from the linear regression analysis for each of the ten refrigerators are displayed in Table 5. The refrigerators in townhouses $\#_{4}$ and $\$$. 9 have low $R^{2}$ for energy consumed, $E$, vs differential temperatures, $\Delta \mathrm{T}_{\mathrm{M}}$ or $\Delta \mathrm{T}_{\mathrm{F}}$. As shown in Figures 22 and 23, the data points of $\mathrm{E} v \mathrm{~g} \Delta \mathrm{T}_{\mathrm{M}}$ or $\Delta \mathrm{T}_{\mathrm{F}}$ for both townhouses show random scatter. Therefore, low $\mathrm{R}^{2}$ might be due to data being recorded incorrectly or the physical malfunctioning of the refrigerators. The fitted straight lines are almost horizontal and even show a negative slope of $\mathrm{E}$ vs $\Delta \mathrm{T}_{\mathrm{M}}$; i.e., $\alpha_{1}$ is negative. Another reason for the observed behavior of the data for the refrigerator in townhouse 非 is that only approximately thirty days of data are available, excluding partial days. There might be insufficient data to determine the results accurately. Therefore, the refrigerators in townhouses $\$$ 作 and 1 9 could not be represented correctly by the mathematical model of equation 1 . 
As for refrigerators in townhouses 非 1 and 非, the low values or $\mathrm{R}^{2}$ from $\mathrm{E}$ vs $\Delta \mathrm{T}_{\mathrm{M}}$ again were due to random scatter of data and also the small variations of $\Delta \mathrm{T}_{\mathrm{M}}$, approximately $5^{\circ} \mathrm{F}$, for refrigerator in townhouse 非 1 , as given in Figure 24. The larger values of $R^{2}$ from $E$ vs $\Delta T_{F}$ indicates for these townhouses the energy consumption is better correlated with the differential freezer temperatures, as illustrated in Figure 25 . In townhouse 非, there is a highly correlated relationship between energy consumption, $E$, and the number of main-section door openings, $\mathrm{ND}_{\mathrm{M}}$, of refrigerator.

Furthermore, Figures 24 and 25 also indicated that these two refrigerators were operated at the same range of $\Delta \mathrm{T}_{\mathrm{F}}$, while $\Delta \mathrm{T}_{\mathrm{M}}$ of the refrigerator in townhouse 非 1 is much higher than that in townhouse 非2. Hence, the average daily energy consumed by the refrigerator in townhouse 非 1 is slightly higher than that in townhouse 非2。

In general, the correlation coefficient $\mathrm{R}^{2}$ had much higher values in temperature differences, $\Delta \mathrm{T}_{\mathrm{M}}$ and $\Delta \mathrm{T}_{\mathrm{F}}$, than those in door openings, with the exceptions discussed previously. That implies that from the linear model of equation 1 , the differential temperature between kitchen and refrigerator (either main section or freezer section) affects energy usage more than door openings. The second independent variable chosen for multiple regression analysis may be either the daily number of door openings or the length of door-opening times, since they are somewhat related, as indicated in their hourly profiles (see Figures 3, 5, 6, 7 , and 8). For example, an attempt to fit the refrigerator energy usage, $E$, in townhouse $\beta^{8}$ as a function of temperature differences between the kitchen and main section, $\Delta \mathrm{T}_{\mathrm{M}}$, and number of main-section door openings, $N D_{M}$ is as follows. The multiple regression relationship is given by

$$
E=\beta_{0}+\beta_{1}\left(\Delta T_{M}\right)+\beta_{2}\left(N D_{M}\right)
$$

where $\mathrm{E}$ is the daily energy consumption in $\mathrm{kWh}, \Delta \mathrm{T}_{\mathrm{M}}$ is the temperature difference between kitchen and main section of refrigerator in degree $F$, and $\mathrm{ND}_{\mathrm{M}}$ is the daily number of main-section door openings. The coefficients of equation 2 were found to be $B_{0}=1.29, B_{1}=0.11$ and $B_{2}=$ 0.007 , where $B_{2}$ is the coefficient denoting energy used in $\mathrm{kWh}$ per each door opening. From coefficients of equations 1 and 2 , note that $\beta_{1}=\alpha_{1}$, which implies the effect of differential temperature is fairly steady. The correlation coefficients $\mathrm{R}^{2}$ of equation 2 increased to 0.822 and the standard deviation was reduced to $\sigma_{\varepsilon}=0.22$. This means equation 2 is a better model than equation 1. The precision gained in standard error with equation 2 is 60 percent, a 10 percent improvement from that with equation 1 . Figure 28 is a sketch of predicted energy usage from equation 2 and the data points from measurements. 
Table 6 gives the regression coefficients and standard deviation for refrigerators in each townhouse. With some exceptions, the majority values of $R^{2}$ have been increased by using a two-parameter model, as can be seen by comparing Table 6 and Table 5. Therefore, it can be concluded that equation 2 is a better mathematical model than equation 1 for predicting daily performance of the standard refrigerators.

\section{DISCUSSION OF RESULTS}

In order to evaluate the performance of different refrigerator models, a comparison of energy consumption of each refrigerator under the same conditions from its regression coefficients is a proper approach. The overall average values of variables for all ten refrigerators is given in Table 7. The normalized energy consumption of each refrigerator was calculated from its regression coefficients $\beta_{0}, \beta_{1}$ and $\beta_{2}$, Table 6 , and overall average values, Table 7. Four combinations of variables were considered in each case, as shown in the following expressions:

$$
\begin{aligned}
& E_{M N}=\beta_{0}+\beta_{1}\left(\overline{\Delta T}_{M}\right)+\beta_{2}\left(\overline{N D}_{M}\right) \\
& E_{F N}=\beta_{0}+\beta_{1}\left(\overline{\Delta T}_{F}\right)+\beta_{2}\left(\overline{N D}_{F}\right) \\
& E_{M t}=\beta_{0}+\beta_{1}\left(\overline{\Delta T}_{M}\right)+\beta_{2}\left(\overline{t D}_{M}\right) \\
& E_{F t}=\beta_{0}+\beta_{1}\left(\overline{\Delta T}_{F}\right)+\beta_{2}\left(\overline{t D}_{F}\right)
\end{aligned}
$$

where $E_{M N}, E_{F N}, E_{M t}$ and $E_{F t}$ are normalized energy consumptions calculated from various combinations of overall average values, given in Table 7, with their regression coefficients.

These results are presented in groups according to their type of model, in Table 8 , together with the actual measurements of energy consumption and differential temperature between kitchen and refrigerators. Except for the refrigerator in townhouse $\#^{7}$, the four values of energy consumption $\left(E_{M N}, E_{F N}, E_{M t}\right.$ and $E_{F t}$ ) of each refrigerator are within the range of \pm 5 percent and these values could be considered as the energy usage of each refrigerator under usage conditions.

The refrigerator in townhouse $\# 7$ was operated at a fairly high freezer temperature of $14^{\circ} \mathrm{F}$, as compared to the overall average freezer temperature of $4.8^{\circ} \mathrm{F}$. The average differential temperature between its kitchen and freezer was $65.6^{\circ} \mathrm{F}$, as compared to the overall average value of $73.6^{\circ} \mathrm{F}$. However, its average main-section temperature was measured to be at $35^{\circ} \mathrm{F}$, which is close to the overall value of $36.4^{\circ} \mathrm{F}$. By using the normalized freezer temperature difference, $\Delta \mathrm{T}_{\mathrm{F}}=42^{\circ} \mathrm{F}$, to calculate the energy consumptions, $E_{F N}$ and $E_{F t}$, the freezer temperature would need to be decreased or $\Delta \mathrm{T}_{\mathrm{F}}$ would have to be increased by $18^{\circ} \mathrm{F}$ or about 
12 percent. Hence, the values of $E_{F N}$ and $E_{F t}$ will be much higher than $E_{M N}$ and $E_{M t ̧}$, since $\Delta T_{M}$ was decreased only about $2.7^{\circ} \mathrm{F}$ or 6 percent. For comparison purposes, $E_{F N}$ and $E_{F t}$ are more realistic values to use under the normalized condition for the refrigerator in townhouse 非 7 .

It should also be pointed out that, according to the field measurements, it is possible to reduce energy consumption by maintaining a higher freezer temperature. Usually running freezer temperature of a refrigerator at an average value of $14^{\circ} \mathrm{F}$ would not be recommended by food scientists [5] or for laboratory tests. When operating the refrigerator in townhouse $\equiv^{7} 7$ at this freezer temperature, energy consumption was reduced by 18 percent as compared to the normal condition.

Table 8 and Figure 29 also show that the energy consumption of refrigerators increases with their physical size, as expected. However, the energy consumption of the refrigerator in townhouse 非 4 , as compared to other $14.7 \mathrm{ft}^{3}$ models, do not fit the attempted correlation.

For the purpose of simplification, an average value $\bar{E}$ for these four cases was considered to be the normalized energy consumption per day for the refrigerator in each townhouse. These values are also included at the last column in Table 8 . The relationship between the daily normalized energy consumption and physical size of refrigerators also can be seen to be linear. Again, regression analysis was utilized to fit a straight line for these data. Figure 29 shows the data points as well as the regression line for refrigerators in all townhouses except the one in townhouse 非 3 . This refrigerator was a manual-defrost model and the rest were frost-free models.

Table 9 gives the parameters from the regression analysis. From Figure 29, the predicted value of $\bar{E}$ was found to be $3.54 \mathrm{kWh}$ for $V=11.5 \mathrm{ft}^{3}$. Comparing it to $E_{3}=2.14 \mathrm{kWh}$, the energy savings between a manual-defrost model and the frost-free model with this size is 1.4 $\mathrm{kWh}$, or about 40 percent per day. As for other size models, there was no valid information available to make estimations. However, the results of the laboratory test of refrigerators by Mulroy et al. [6] were found to be quite interesting when compared with Figure 29. Under $75^{\circ} \mathrm{F}$ kitchen temperature with door-opening conditions, the daily energy consumption for a $14.7 \mathrm{ft}^{3}$ frost-free refrigerator was found to be $5.12 \mathrm{kWh}$ * The predicted value in Figure 29 is $5.3 \mathrm{kWh}$, only a 3.5 percent difference. As for the manual-defrost model, the daily energy usage for the $14.7 \mathrm{ft}^{3}$ refrigerator was found to be $2.91 \mathrm{kWh} *$, which is 38 percent below the expected value, $4.7 \mathrm{kWh}$, for the frostfree model in the same size. Consequently, the regression line in Figure 29 indicates the differences in energy consumption per day for various sizes of frost-free refrigerators under the normal usage pattern. The energy usage was found to be $0.55 \mathrm{kWh}$ for each additional cubic foot of volume for the frost-free model. The approximate

* Average value for the two relative humidity settings. 
percentage of saving in energy consumption of refrigerators from a frost-free model to a manual-defrost model could also be estimated from Figure 29 and the above calculations.

\section{CONCLUSION}

The hourly profiles of the refrigerator showed that occupants opened the doors much more at lunch time and dinner time. The door openings usually dropped to zero from midnight to 6:00 am. The hourly energy consumption was consistent with this pattern (heaviest at lunch and dinner times) except at the time immediately following the refrigerator self-defrost cycle, when additional energy was used to reduce the temperature inside the refrigerator.

By analyzing the daily performance of residential refrigerators, it was concluded that the differential temperature between the kitchen and the refrigerator dominated its energy usage, with lesser, though still important, effects from door openings.

The daily energy consumption is linearly related to the physical sizes of refrigerators. It was estimated that there would be about $0.55 \mathrm{kWh}$ increase per day for each cubic foot increase in volume for the frostfree refrigerators. The energy conserved by using a manual defrost refrigerator was found to be approximately 40 percent of that for the frost free model. 
5. TABLES AND FIGURES

TABLE 1

REFRIGERATOR PHYSICAL CHARACTERISTICS

\begin{tabular}{|c|c|c|c|c|}
\hline $\begin{array}{l}\text { Townhouse } \\
\text { Number }\end{array}$ & Mode1* & $F t^{3}$ & $\begin{array}{l}\text { Frost } \\
\text { Free }\end{array}$ & $\begin{array}{l}\text { No. of } \\
\text { Doors }\end{array}$ \\
\hline 1 & $\mathrm{TBF}-15 \mathrm{~S}$ & 14.7 & yes & 2 \\
\hline 2 & $\mathrm{TBF}-15 \mathrm{~S}$ & 14.7 & yes & 2 \\
\hline 3 & $\mathrm{TA}-12 \mathrm{~S}$ & 11.5 & no & 1 \\
\hline 4 & TBF-15S & 14.7 & yes & 2 \\
\hline 5 & $\mathrm{TBF}-15 \mathrm{~S}$ & 14.7 & yes & $2-$ \\
\hline 6 & $18-\mathrm{CMB}$ & 18.0 & yes & 2 \\
\hline 7 & $\mathrm{TBF}-16 \mathrm{~S}$ & 15.6 & yes & 2 \\
\hline 8 & $\mathrm{TBF}-16 \mathrm{~S}$ & 15.6 & yes & 2 \\
\hline 9 & $\mathrm{TFF}-15 \mathrm{~J}$ & 14.7 & yes & 2 \\
\hline 10 & $\mathrm{TBF}-19 \mathrm{D}$ & 19.0 & yes & $2-s$ \\
\hline
\end{tabular}

* All refrigerator models were from the same manufacturer, as supplied by the developer or purchased by the occupants. 
TABLE 2

OCCUPANT AND TOWNHOUSE CHARACTERISTICS

\begin{tabular}{|c|c|c|c|c|}
\hline $\begin{array}{l}\text { Townhouse } \\
\text { Number }\end{array}$ & $\begin{array}{l}\text { Number of } \\
\text { Adults }\end{array}$ & $\begin{array}{l}\text { Number of } \\
\text { Children }\end{array}$ & $\begin{array}{c}\text { Children's } \\
\text { Ages }\end{array}$ & $\begin{array}{r}\text { Number of } \\
\text { Bedrooms }\end{array}$ \\
\hline 1 & 2 & 2 & 6,8 & 3 \\
\hline 2 & 2 & 1 & 6 & 3 \\
\hline 3 & 2 & 1 & 3 & 2 \\
\hline 4 & 2 & 3 & $6,7,9$ & 3 \\
\hline 5 & 2 & 2 & 10,13 & 3 \\
\hline 6 & 2 & 2 & 10,13 & 4 \\
\hline 7 & 2 & 2 & 2,4 & 3 \\
\hline 8 & 2 & 2 & 1,3 & 3 \\
\hline 9 & 3 & 1 & 15 & 3 \\
\hline 10 & 2 & 2 & 2,6 & $\begin{array}{c}2 \text { converte } \\
\text { to } 3\end{array}$ \\
\hline
\end{tabular}


TABLE 3 SUNRLARY OF AVERAGE HOURLY ENERGY AND DOOR OPENINGS OF THE REFRIGERATOR IN EACH TOWNHOUSE

\begin{tabular}{|c|c|c|c|c|c|c|c|c|c|c|c|c|c|c|c|c|c|c|c|c|c|c|c|c|}
\hline \multirow{2}{*}{ 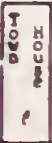 } & \multicolumn{24}{|c|}{ ENERGY CONSUMED (KMH) BY HOURS } \\
\hline & 1 & 2 & 3 & 4 & 5 & 6 & 7 & 8 & 9 & 10 & 11 & 12 & 13 & 14 & 15 & 16 & 17 & 18 & 19 & 20 & 21 & 22 & 23 & 26 \\
\hline 1 & 0.14 & 0.19 & 0.18 & 0.17 & 0.18 & 0.20 & 0.21 & 0.29 & 0.20 & 0.20 & 0.18 & 0.21 & 0.21 & 0.20 & 0.23 & 0.23 & 0.23 & 0.24 & 0.25 & 0.25 & 0.25 & 0.23 & 0.21 & 0.19 \\
\hline 2 & 0.18 & 0.16 & 0.16 & 0.24 & 0.16 & 0.14 & 0.15 & 0.17 & 0.20 & 0.20 & 0.18 & 0.21 & 0.22 & 0.20 & 0.20 & 0.20 & 0.23 & 0.24 & 0.24 & 0.23 & 0.22 & 0.22 & 0.20 & 0.18 \\
\hline 3 & 0.07 & 0.07 & 0.07 & 0.07 & 0.07 & 0.06 & 0.08 & 0.06 & 0.08 & 0.08 & 0.08 & 0.09 & 0,08 & 0.08 & 0.08 & 0.00 & 0.00 & 0.20 & 0.09 & 0.00 & 0.09 & 0,08 & 0.08 & 68 \\
\hline 4 & 0.28 & 0.28 & 0.28 & 0.28 & 0.27 & 0.27 & 0.27 & 0.28 & 0.28 & 0.28 & 0.28 & 0.25 & 0.30 & 0.29 & 0.28 & 0.2 & 0.29 & 0.30 & 0.30 & 0.30 & 0.30 & 0.30 & 0.29 & 0.29 \\
\hline 5 & 0.2 & 0.1 & 0.18 & 0.19 & 0.18 & 0.18 & 0.17 & 0.20 & 0.20 & 0.21 & 0.21 & 0.20 & 0.2 & 0.20 & 0.2 & 0.21 & 0.21 & 0.24 & 0.23 & 0.21 & 0.21 & 0.23 & 0.22 & 0.20 \\
\hline 0 & 0.29 & 0.2 & 0.25 & 0.29 & 0.23 & 0.2 & 0.25 & 0.29 & 0.2 & 0.29 & 0.31 & 0.25 & 0.3 & 0.30 & 0.29 & 0.28 & 0.33 & 0.35 & 0.36 & 0.36 & 0.33 & 0.30 & 0.30 & 0.30 \\
\hline 7 & 0.25 & 0.23 & 0.20 & 0.18 & 0.18 & 0.20 & 0.18 & 0.20 & 0.26 & 0.24 & 0.24 & 0.26 & 0.20 & 0.26 & 0.26 & 0.25 & 0.27 & 0.29 & 0.28 & 0.26 & 0.24 & 0.23 & 0.22 & 0.22 \\
\hline$B$ & 0.25 & 0.2 & 0.26 & 0.24 & 0.26 & 0.23 & 0.2 & 0,2 & 0.28 & 0.28 & 0.28 & 0.29 & 0.28 & 0.27 & 0.27 & 0.28 & 0.29 & 0.29 & 0.30 & 0.30 & 0.30 & $0.2 \pi$ & 0.27 & 0.26 \\
\hline 9 & 0.18 & 0.18 & 0.18 & 0.17 & 0.18 & $0.2 x$ & 0.1 & 0.21 & 0.21 & 0.28 & 0.21 & 0.23 & 0.21 & 0.21 & 0.22 & 0.22 & 0.23 & 0.25 & 0.2 & 0.23 & 0.22 & 0.20 & 0.20 & 0.19 \\
\hline 10 & 0.35 & 0.35 & 0.35 & 0.33 & 0.32 & 0.32 & 0.3 & 0.32 & 0.32 & 0.35 & 0.34 & 0.35 & 0.38 & 0.34 & 0.35 & 0.35 & 0.35 & 0.36 & 0.37 & 0.36 & 0.36 & 0.36 & 0.35 & 0.34 \\
\hline
\end{tabular}

\begin{tabular}{|c|c|c|c|c|c|c|c|c|c|c|c|c|c|c|c|c|c|c|c|c|c|c|c|c|}
\hline & \multicolumn{24}{|c|}{ NEMBER OF MAIN SECTION DOOR OPENINGS BY HOURS } \\
\hline 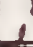 & 1 & 2 & 3 & 4 & 5 & 6 & 7 & 8 & 9 & 10 & 11 & 12 & 13 & 14 & 15 & 16 & 17 & 18 & 19 & 20 & 21 & 22 & 23 & \\
\hline & 0.12 & 0 & 0.04 & 0 & 0.06 & 2.64 & 4.12 & .67 & 12.34 & ss & & 251 & 1.42 & 1.59 & 2.62 & 2,12 & 3.74 & 4.70 & & 3.17 & 1.66 & 1,10 & 0.51 & 0,29 \\
\hline & 0.25 & 0.09 & 2,16 & e & e & 0,2 & 1.17 & 2.95 & 4.67 & 3.14 & 2.59 & 4.62 & 4.06 & 2.10 & 2.07 & 2.37 & 4.90 & 5.88 & 3,90 & 2.94 & 2.49 & 2.67 & 0.88 & 0.33 \\
\hline 3 & 0.17 & 0 & 0 & 0.07 & 0 & 0.40 & 1.5 & 2.45 & 2.97 & 2.42 & 2.32 & 2.45 & 2.07 & 2.00 & 1.82 & 2.43 & 3.87 & 7.50 & 3.91 & 2.74 & 3.56 & 1.95 & 1.26 & 0.74 \\
\hline 4 & 0.05 & 0 & 0 & 0 & 0.02 & 0.88 & 0.40 & 2.9 & 2.45 & 2.10 & 3.77 & 3.84 & 1.77 & 1.25 & 3.18 & 2.20 & 3.71 & 5.22 & 3.38 & 2.28 & 1.40 & 1.19 & 0.67 & 0.21 \\
\hline 5 & 0.16 & 0.11 & 0.11 & 0.03 & 1 & 0.01 & 0.74 & 1.79 & 2.12 & 1.89 & 1.37 & 1.79 & 1.25 & 0.97 & 1.47 & 1.04 & 2.41 & 3.15 & 1.63 & 1.07 & 2.78 & 2.02 & 0.61 & 0.36 \\
\hline 6 & 0,42 & 0.09 & 0.25 & 0.23 & 0.17 & 0.06 & 1.33 & 2.25 & 2.44 & 3.17 & 3.13 & 4.00 & 2.98 & 1.64 & 1.53 & 1.95 & 3.42 & 6.25 & 3.59 & 2.30 & 2.33 & 1.86 & 2.05 & 0.95 \\
\hline 7 & 0.2 & 0.02 & 0 & 0 & 0.05 & 1.08 & 0.14 & 1.54 & 7.40 & 4.93 & 3.99 & 5.73 & 4.96 & 2.28 & 3.49 & 3.75 & 5.43 & 8.23 & 4.86 & 1.70 & 1.57 & 0.65 & 0.25 & 0.21 \\
\hline 8 & 0.18 & 0.02 & 0 & 0 & 0 & 0.25 & 1.90 & 3.80 & 5.27 & 4.05 & 4.78 & 4.20 & 4.10 & 2.19 & 2.85 & 3.39 & 4.42 & 6.00 & 5.72 & 4.81 & 3.06 & 1.02 & 0.75 & 0.56 \\
\hline 9 & 0.05 & 0.20 & 0.0 & 0.05 & 0.03 & 0.76 & 1.16 & 5.62 & 4.29 & 3.25 & 2.76 & 4.19 & 2.94 & 2.48 & 2.86 & 2.83 & 5.05 & 5.55 & 2.68 & 1.42 & 2.34 & 2.08 & 0.72 & 0.50 \\
\hline 10 & 0.16 & 0.01 & 0 & 0 & 0.03 & 0.64 & 0.04 & 0.25 & 2.84 & 5.23 & 2.30 & 2.90 & 3.16 & 1.73 & 1.61 & 1.03 & 1.21 & 5.09 & 4.16 & 3.20 & 2.17 & 1.34 & 1.05 & 0.30 \\
\hline
\end{tabular}

\begin{tabular}{|c|c|c|c|c|c|c|c|c|c|c|c|c|c|c|c|c|c|c|c|c|c|c|c|c|}
\hline \multirow{2}{*}{ : } & \multicolumn{24}{|c|}{ MUMBER OF FREEZEF } \\
\hline & 1 & 2 & 3 & 4 & 5 & 6 & 7 & 8 & 9 & 10 & 11 & 12 & 13 & 16 & $15^{\circ}$ & 16 & 17 & 18 & 19 & 20 & 21 & 22 & 23 & 24 \\
\hline 1 & 0.0 & 0 & 0.01 & 0 & 0 & 0.05 & 0.12 & 0.07 & 0,21 & 0,09 & 0.49 & 0.73 & 0,44 & 0.71 & 1,71 & 1.15 & 1.34 & 1.25 & 0.91 & 1.76 & 0.90 & 0.77 & 0.11 & 0.11 \\
\hline 2 &. & 1 & 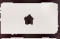 & 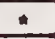 & 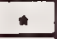 & 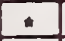 & . & 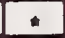 & 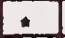 & 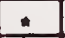 & 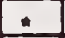 & 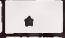 & 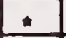 &. & 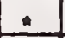 &. & 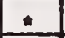 & 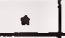 & - &. & 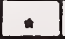 & . & . & . \\
\hline 3 & .. & $\ldots$ & $\ldots$ & $\ldots$ & $\ldots$ & $\ldots$ & $\ldots$ & $\ldots$ & $\ldots$ & m & $\ldots$ & $\ldots$ & $\ldots$ & $\ldots$ & $\ldots$ & $\ldots$ &. & . & \# & $\ldots$ & A. & A & 8 & * \\
\hline 4 & 2 & Le & 0 & 0 & 0 & 0 & 0 & 0,48 & 0.15 & 0.42 & 0.36 & 0.36 & 0.30 & 0.41 & 0,48 & 0,43 & 0.67 & 1.85 & 0.71 & 0.12 & 0.19 & 0.21 & 0.19 & 0 \\
\hline 5 & 0.04 & 0.01 & 0.02 & 0.02 & 0 & 0 & 0.01 & 0.21 & 0.26 & 0.31 & 0.15 & 0.47 & 0.44 & 0.39 & 0.35 & 0.41 & 1.02 & 1.15 & 0.45 & 0.42 & 0.75 & 0.50 & 0.22 & 0.13 \\
\hline 6 & 0.05 & 0.03 & 0.06 & 0.03 & 0.03 & 0 & 0.11 & 0.21 & 0.24 & 0.48 & 0.52 & 1.05 & 0.47 & 0.18 & 0.42 & 0.23 & 0.80 & 1.58 & 0.77 & 0.34 & 0.53 & 0.55 & 0.38 & 0.16 \\
\hline 7 & 0 & 0 & 0 & 0 & e & 0 & 0 & 0.02 & 0.27 & 0.24 & 0.59 & 0.48 & 0.83 & 0.25 & 0.57 & 0.61 & 0.94 & 1.99 & 0.82 & 0.20 & 0.40 & 0.20 & 0.04 & 0 \\
\hline 8 & 0 & 0 & 0 & 0 & 0 & 0.02 & 0.25 & 0.39 & 0.57 & 0.40 & 0.40 & 0.77 & 0.54 & 0.31 & 0.51 & 0.80 & 2.04 & 1.71 & 1.55 & 1.21 & 0.81 & 0.19 & 0.08 & 0.06 \\
\hline 9 & 0.02 & 0.01 & 0 & 0 & 0 & 0.22 & 0.30 & 0.58 & 0.42 & 0.65 & 0.45 & 0.58 & 0.53 & 0.53 & 0.68 & 0.92 & 1.24 & 1.51 & 0.76 & 0.55 & 0.75 & 0.55 & 0.20 & 0.09 \\
\hline 10 & 0.05 & 0 & 0 & 0 & 0.01 & 0.18 & 0 & 0.01 & 0.28 & 0.49 & 0.16 & 0.31 & 0.56 & 0.30 & 0.28 & 0.16 & 0.59 & 1.30 & 0.33 & 0.83 & 0.88 & 0.04 & 0.38 & 0.08 \\
\hline
\end{tabular}

* Missing Data

$\star *$ No Measurements 


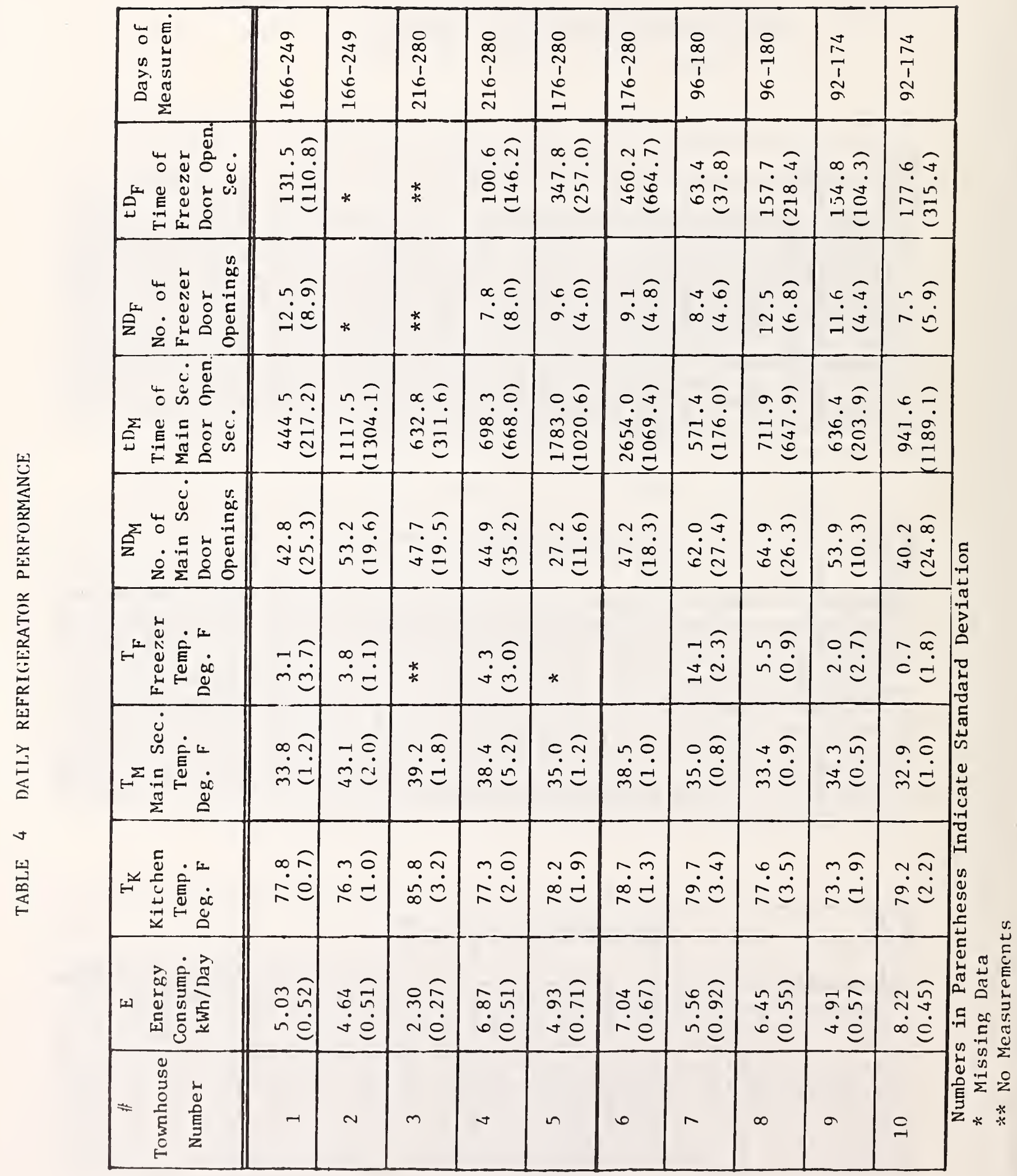




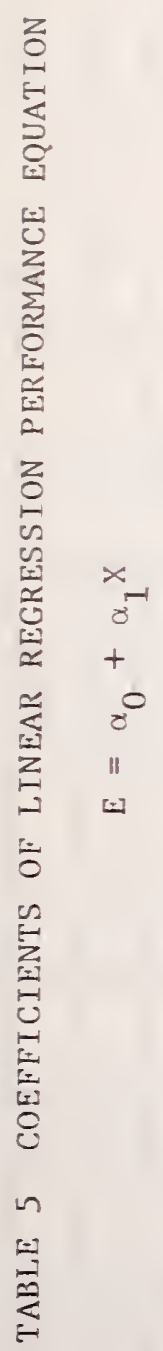

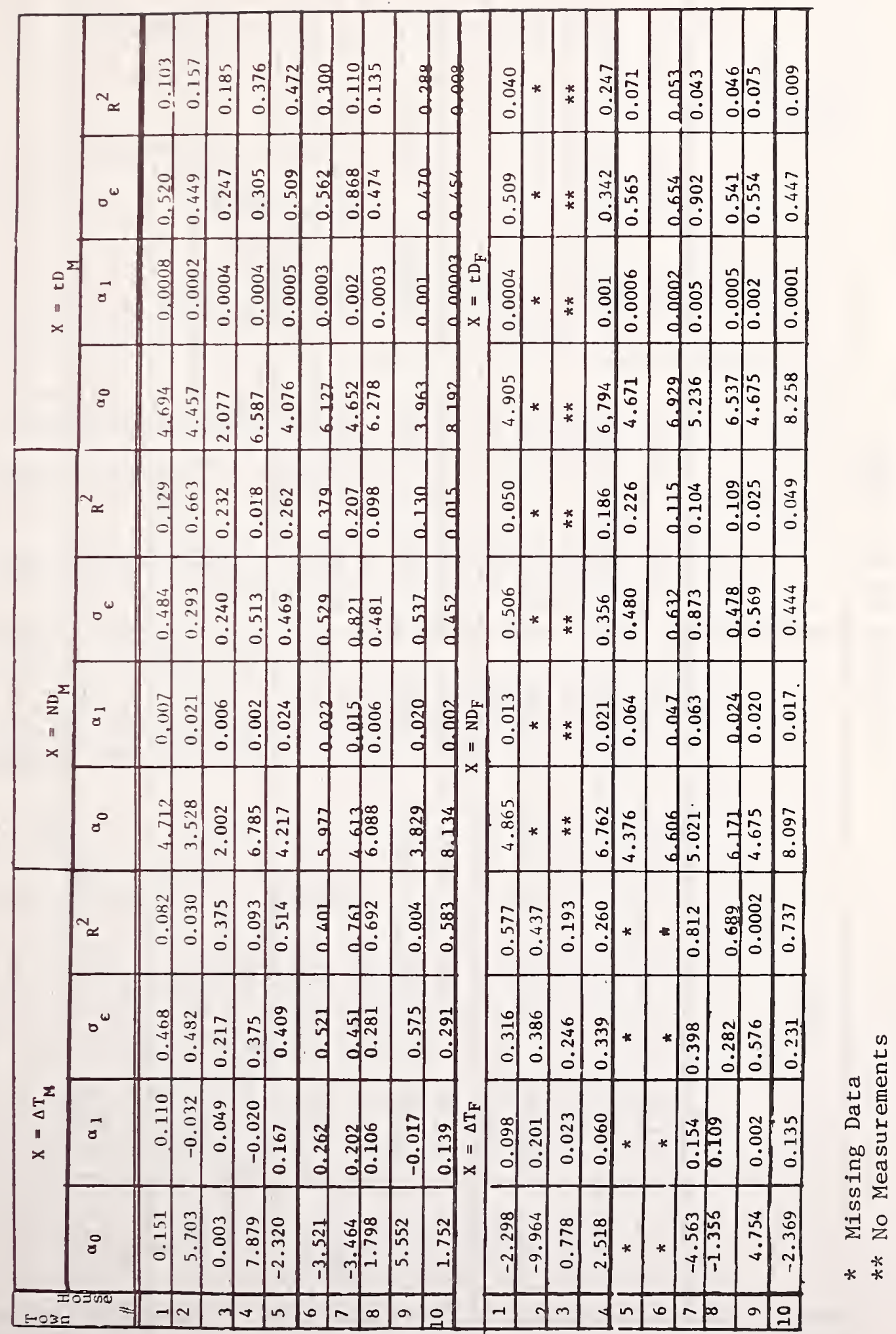




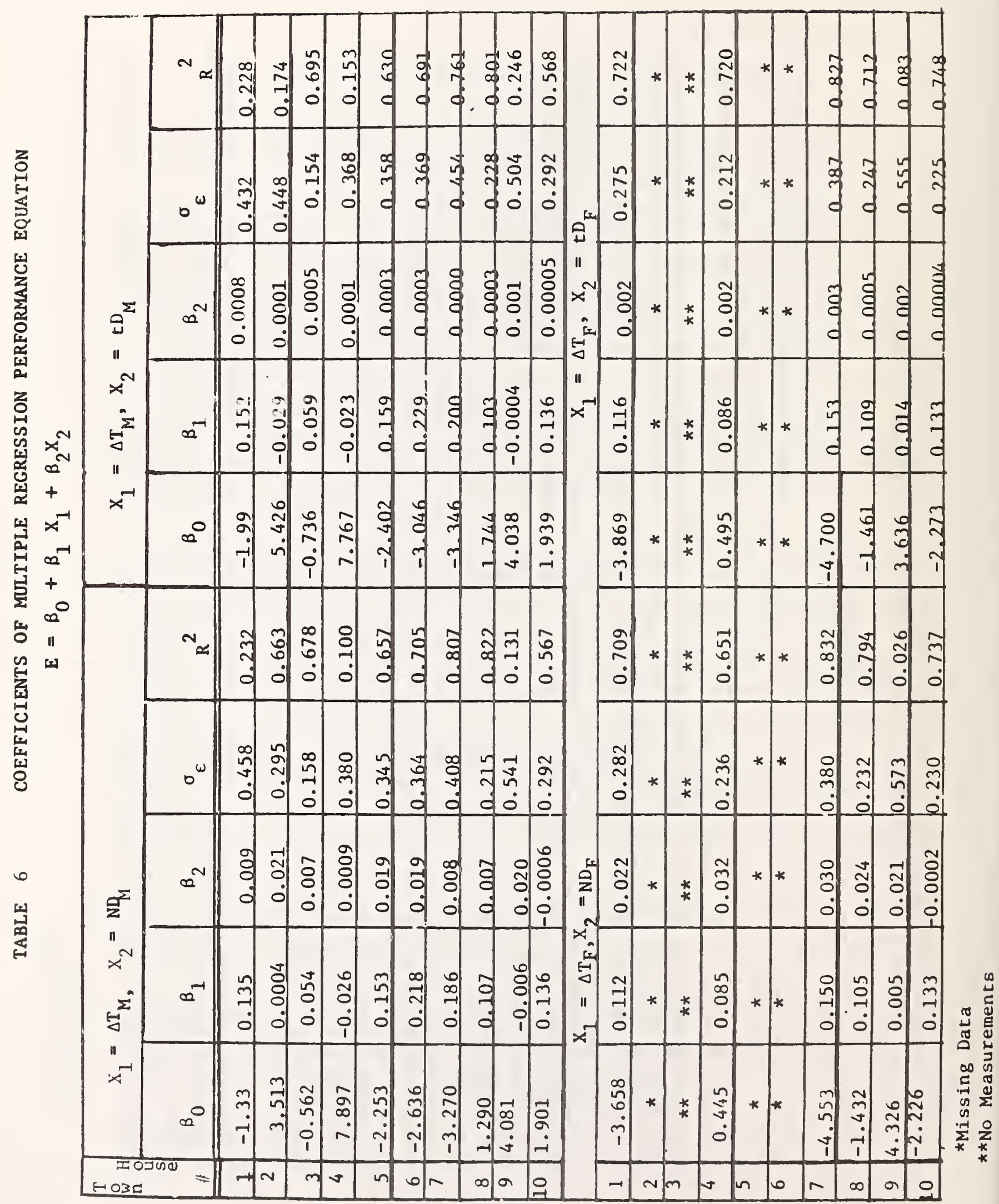


OVERALL VALUES OF THE REFRIGERATORS

\begin{tabular}{|c|c|c|c|}
\hline & ${ }^{\circ} \mathrm{F}$ & Number & Seconds \\
\hline Average Kitchen Temperature $\overline{\mathrm{T}}_{\mathrm{K}}$ & 78.4 & & \\
\hline Average Main Section Temperature $\overline{\mathrm{T}}_{\mathrm{M}}$ & 36.4 & & \\
\hline Average Freezer-Section Temperature $\overline{\mathrm{T}}_{\mathrm{F}}$ & $4 \cdot 8$ & & \\
\hline $\begin{array}{l}\text { Average Temperature Difference } \\
\text { Across Main Section, } \Delta \bar{T}_{M}\end{array}$ & 42.0 & & \\
\hline $\begin{array}{l}\text { Average Temperature Difference } \\
\text { Across Freezer Section, } \Delta \bar{T}_{F}\end{array}$ & 73.5 & & \\
\hline $\begin{array}{l}\text { Average Number Main-Section Door- } \\
\text { openings per Day, } \overline{N D}_{M}\end{array}$ & & 48 & \\
\hline $\begin{array}{l}\text { Average Time of Main Section } \\
\text { Door-openings per day, }{ }^{t} D_{M}\end{array}$ & & & 1019 \\
\hline $\begin{array}{l}\text { Average Number of Freezer Section } \\
\text { Door-openings per day, } \bar{N}_{F}\end{array}$ & & 10 & \\
\hline $\begin{array}{l}\text { Average Time of Freezer Section } \\
\text { Door-openings per day, } \overline{t D}_{F}\end{array}$ & & & 199 \\
\hline
\end{tabular}




\begin{tabular}{|c|c|c|c|c|c|c|c|c|}
\hline & & 8 & $\stackrel{\square}{:}$ & 15 & 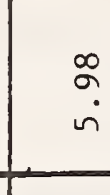 & $\begin{array}{l}z_{0}^{0} \\
0\end{array}$ & & $\stackrel{0}{2}$ \\
\hline 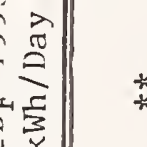 & & & 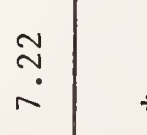 & $\xi$ & $\stackrel{g}{g}$ & $\dot{\leftrightarrow}$ & & $\vec{a}$ \\
\hline 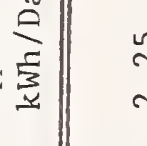 & & $\stackrel{0}{3}$ & $: 3$ & 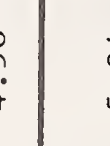 & $\stackrel{\leftrightarrow}{\ddot{u}}$ & 3 & & $\stackrel{8}{=}$ \\
\hline & & & 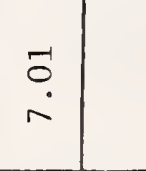 & 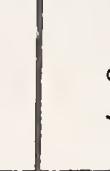 & 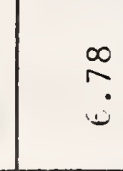 & 1 & & 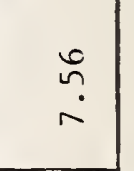 \\
\hline & & å & 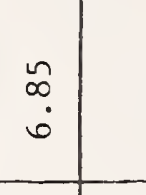 & 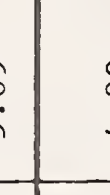 & 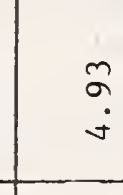 & בै. & & 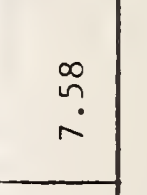 \\
\hline & & {$\left[\begin{array}{c}n \\
\vdots\end{array}\right.$} & : & 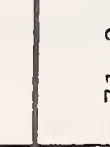 & $\because \dot{0}$ & $\vec{E}$ & & 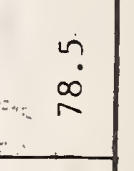 \\
\hline & & $\mathscr{z}$ & 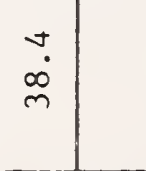 & 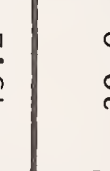 & 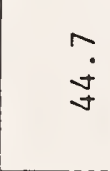 & $\tilde{z}$ & & "a \\
\hline & & $\stackrel{f}{\dot{u}}$ & $:$ & 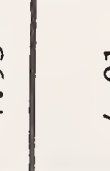 & $\stackrel{\leftrightarrow}{\circ}$ & $\frac{8}{8}$ & & $\frac{z}{8}$ \\
\hline & & & $\Xi$ & 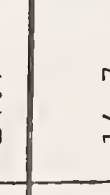 & $\dot{\square}$ & & : & $\stackrel{0}{2}$ \\
\hline & & & & & & & & $=$ \\
\hline
\end{tabular}



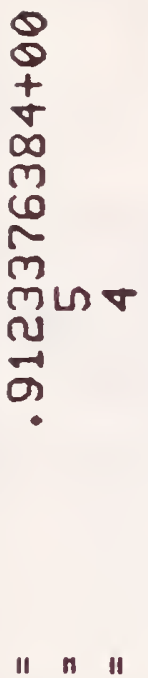

000 000 $+t+$ तo $07 \%$

ดயณ

のレบ

ตับ

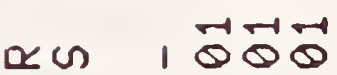

ww $1+t+$

LE $\quad 10 \pi \sigma$

w匹 $\varepsilon \varepsilon$

cur

工田

땀

Z

매

(

1

5 W

વu以

$\mapsto \propto F$

a Wu

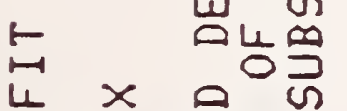

$* * * \begin{aligned} & 1 \\ & 1\end{aligned} * * *$

$* * * * *$

Z 1000

-100 000

वᄄ口 $1+++$

$\supset$ IF 1 Uूष

बिव ।

मEम

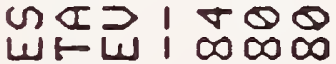

$\alpha$ 딷

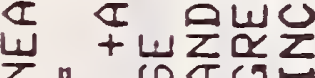

口 O

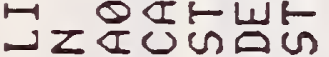
$\alpha \omega 0$

U)

更U

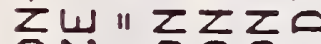

№

o

$=$

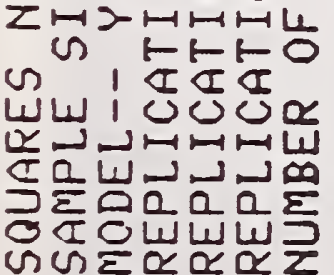

峁

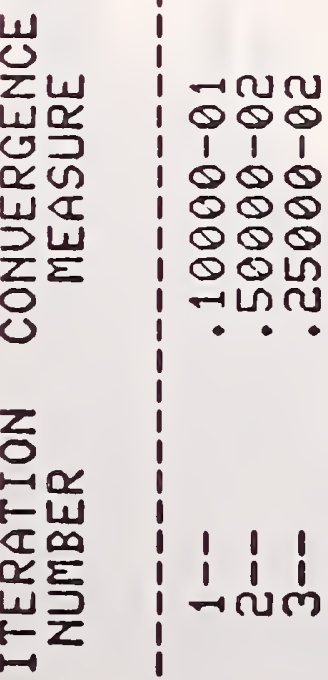

峁

ค 万

is

- $\sim m$

$x \sin$ or

$\alpha \div \sim$

a $\mathrm{a}$

$\frac{1}{1}$

$\smile \smile \smile$

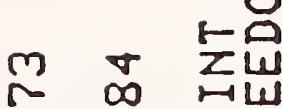

( $m \quad 0 \alpha$

Q 1 a

o $r$

$\nabla m$

$7 m$ ro

N 4

- $\rightarrow$ nu

cor andu

$r a$

पर

In

u

" $"$ "

$\infty \pi$

$\rightarrow \infty$

$r m$

กิ

ज. In

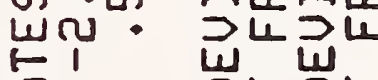

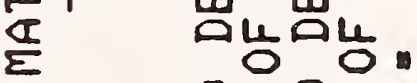

口 0

$\alpha \csc x$

厅山ส山ю下

口w口Wfम

$z \alpha z \alpha \propto 3$

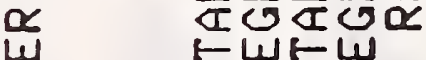

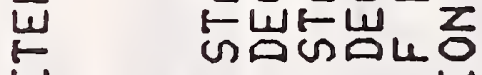

E

중

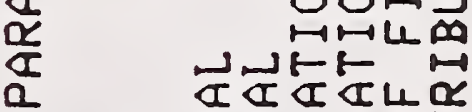

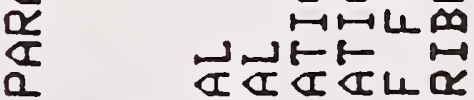

य०

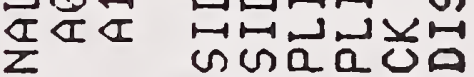

$\mapsto$ एய山س

$u \rightarrow N \quad \alpha \propto \alpha \propto \omega$ 


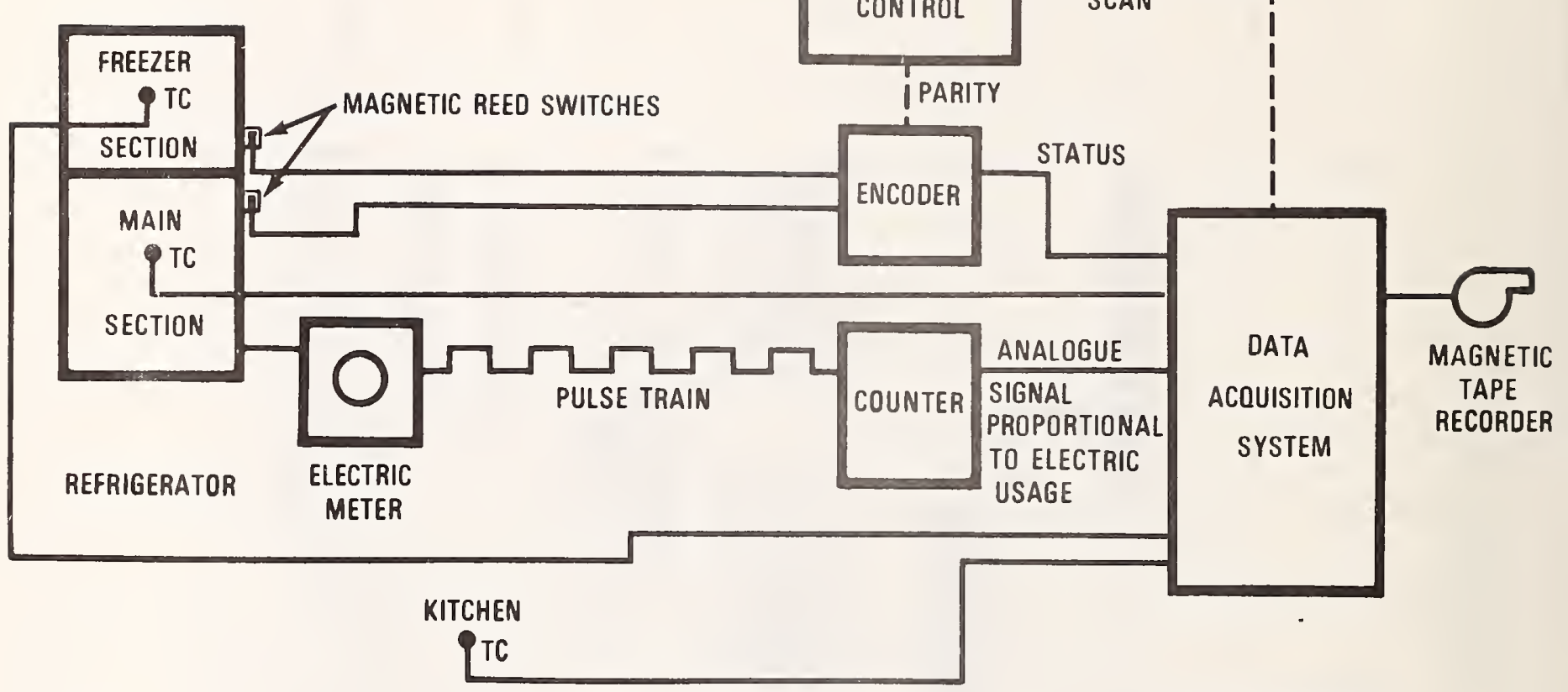

Figure 1 Schematic of Refrigeration Instrumentation

TC - Thermocouple

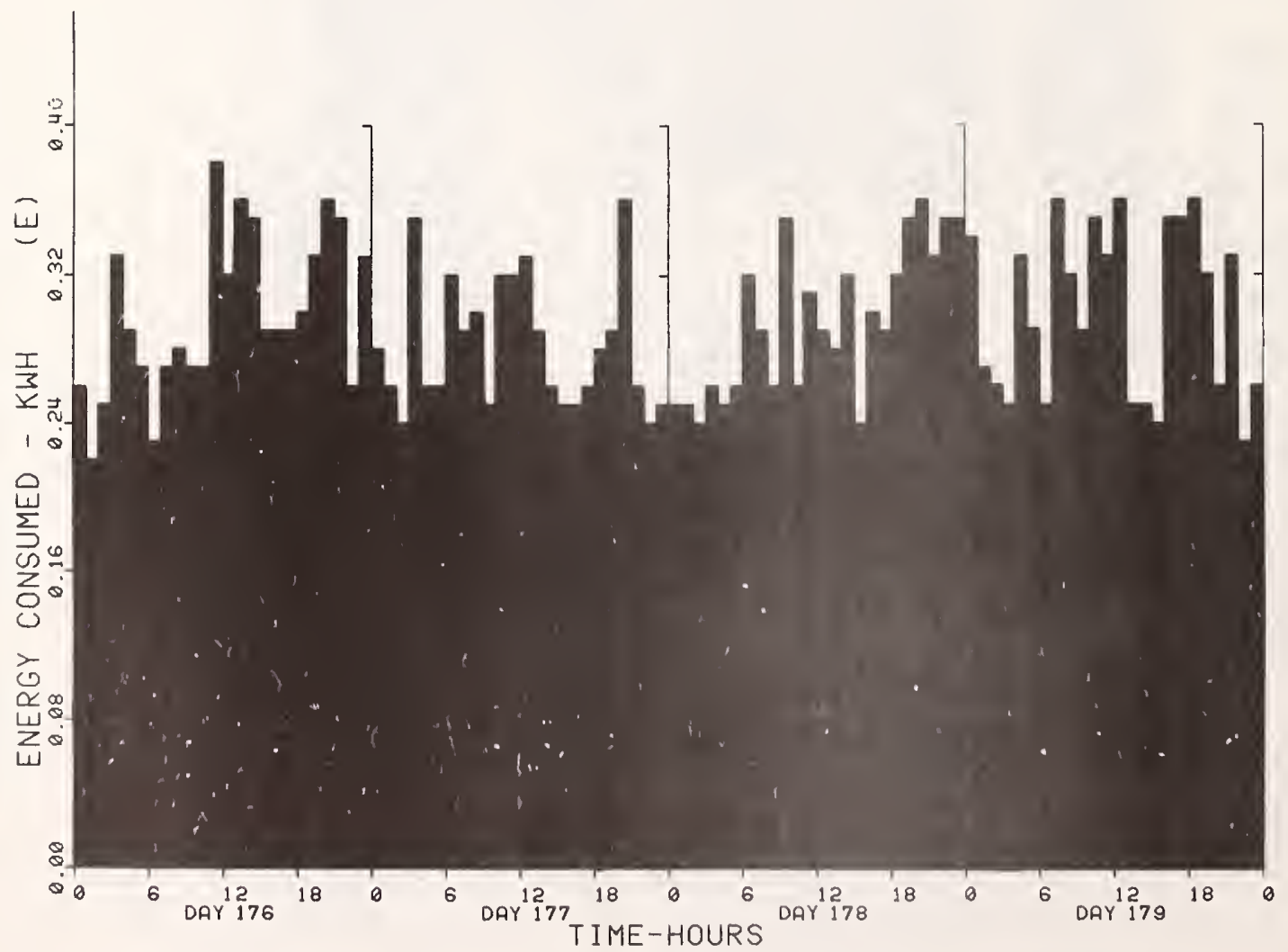

Figure 2 Refrigerator Hourly Energy Consumption (Townhouse 8) 
ن

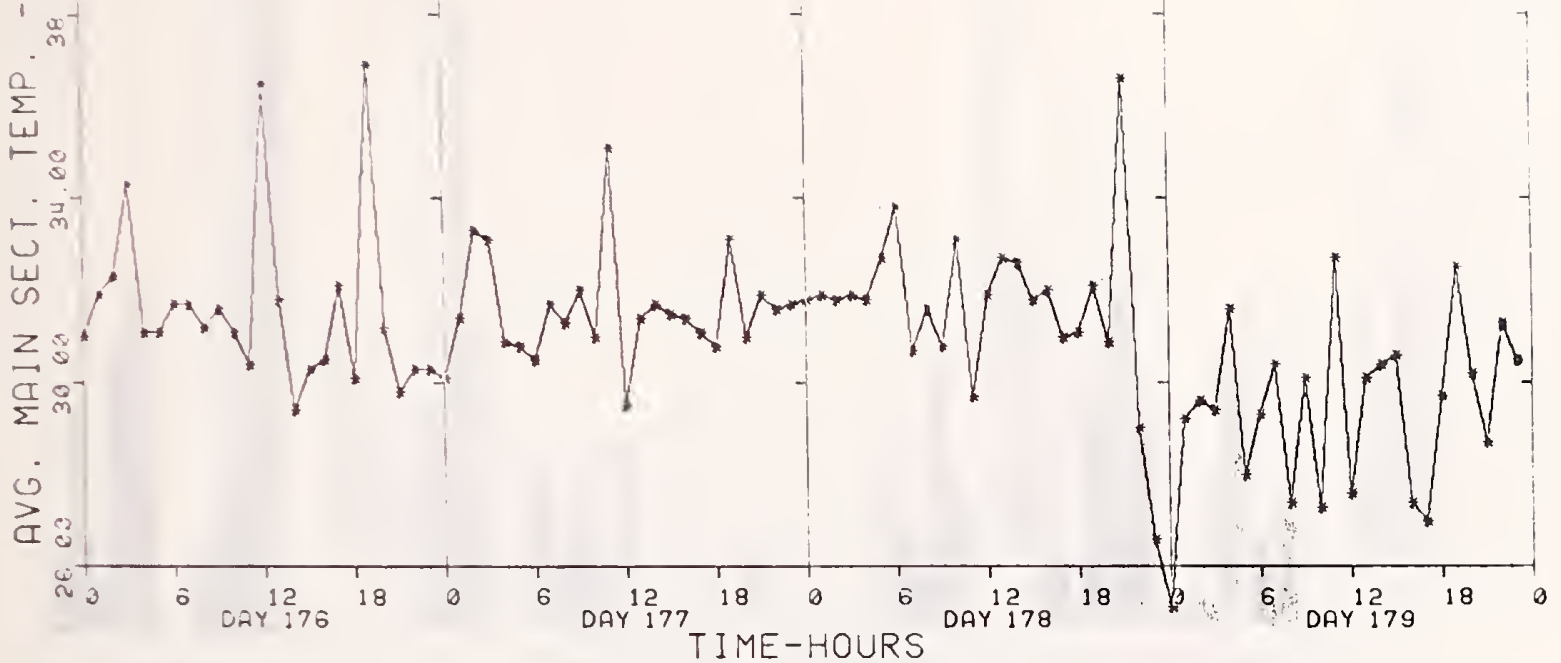

Figure 3 Hourly Main Section Average Temperature (Townhouse 8)

Еே

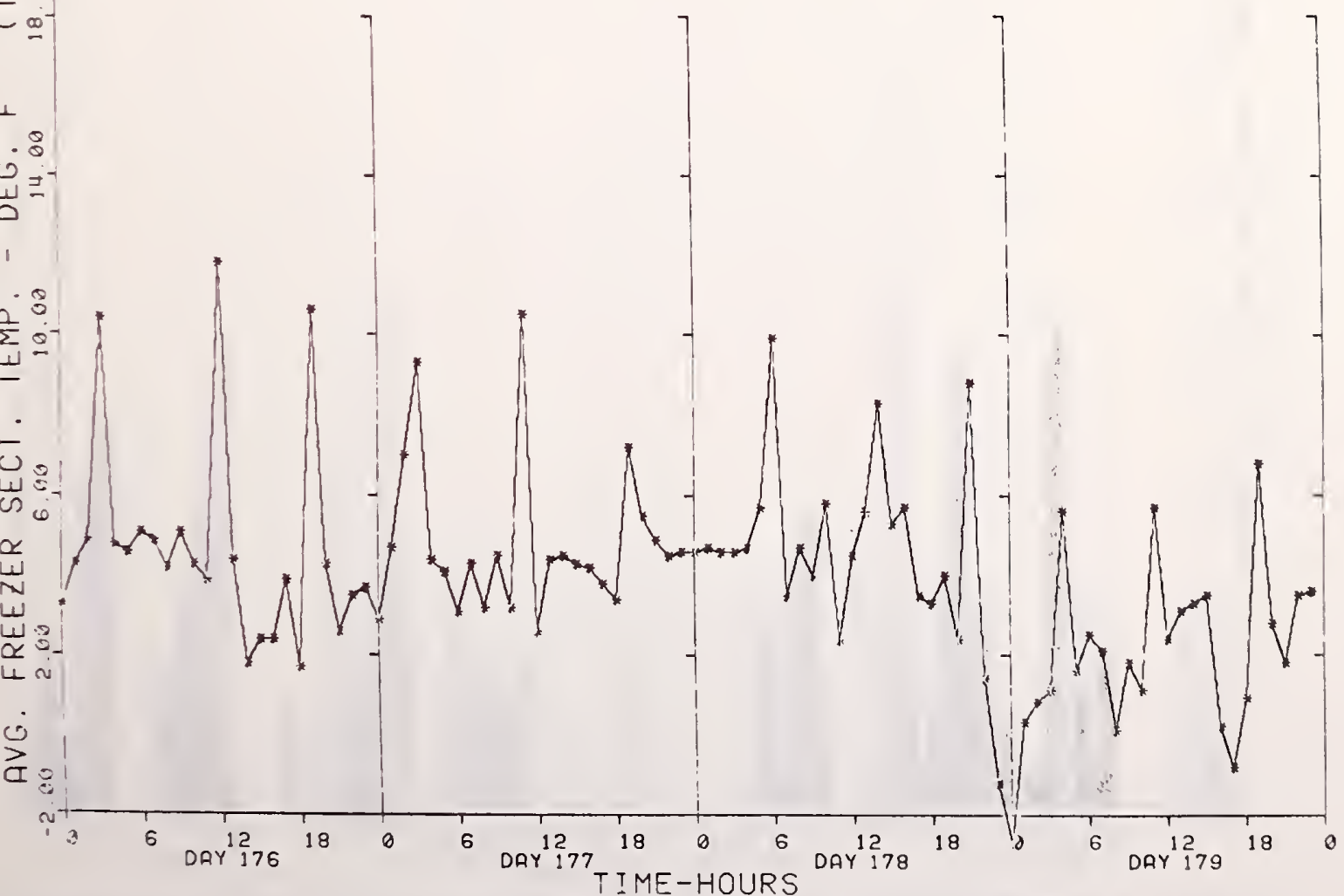

Figure 4 Hourly Freezer Average Temperature (Townhouse 8) 


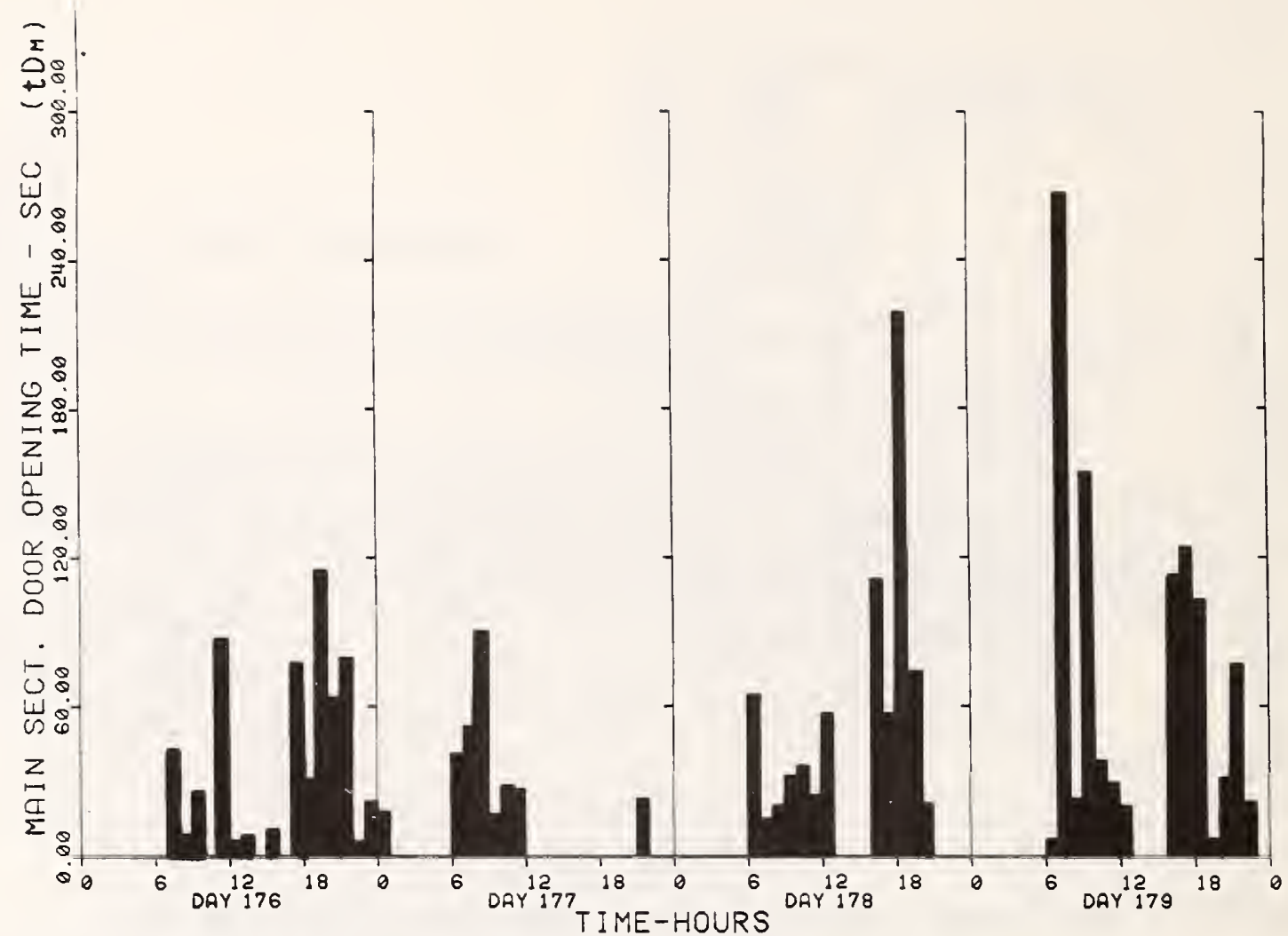

Figure 5 Hourly Main Section Door Opening Time (Townhouse 8)

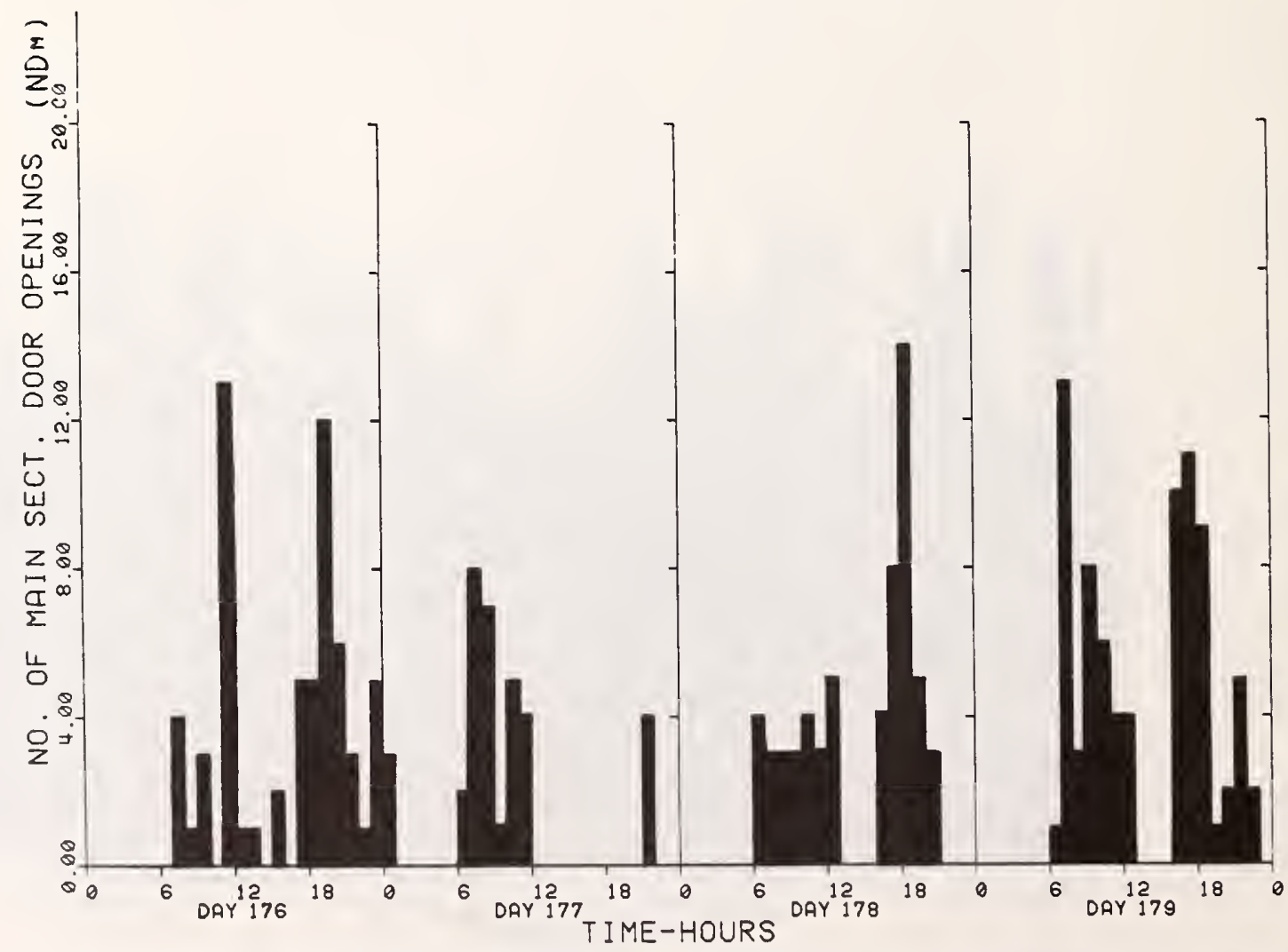

Figure 6 Hourly Number of Main Section Door Openings (Townhouse 8) 


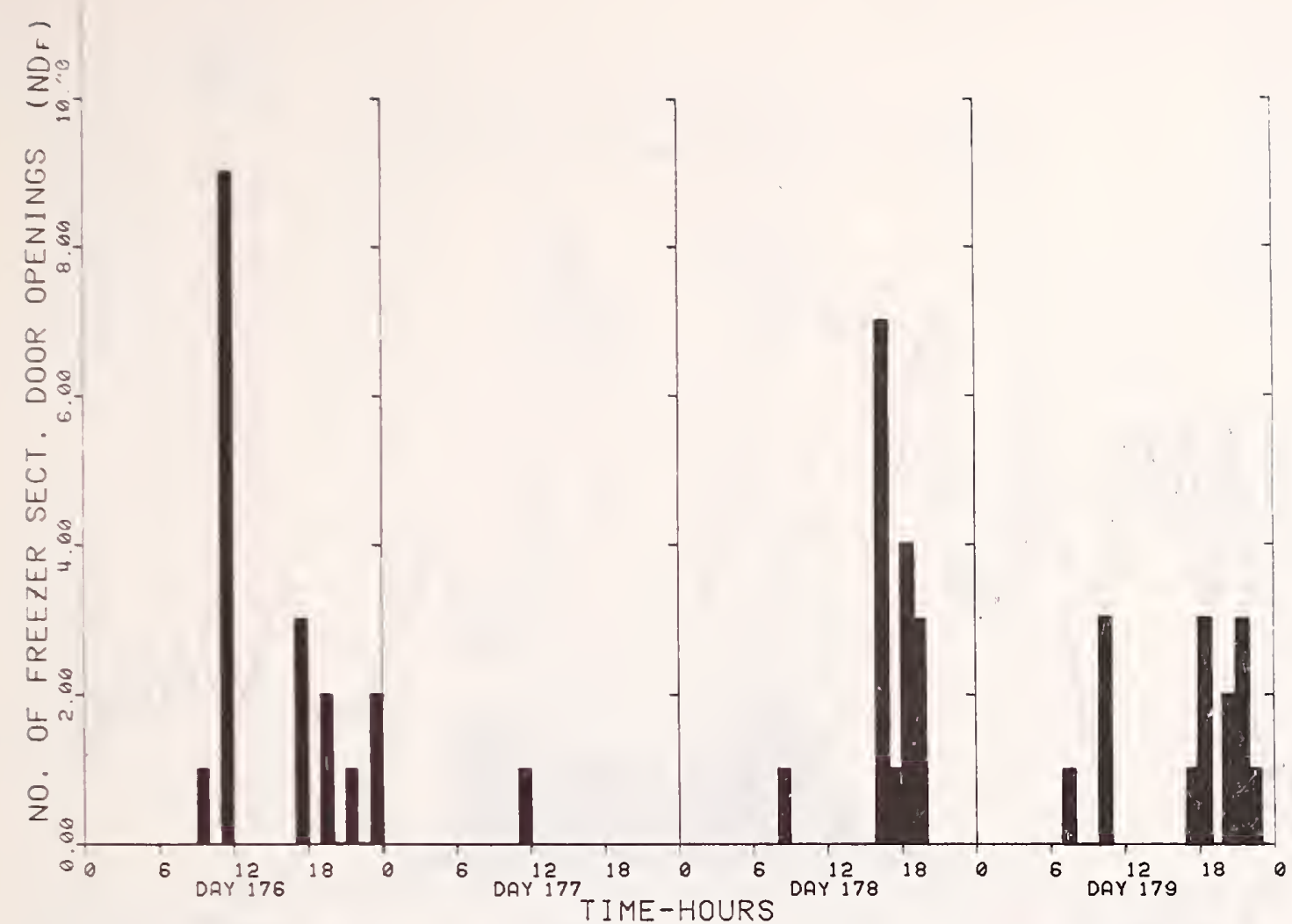

Figure 7 Hourly Number of Freezer Door Openings (Townhouse 8)

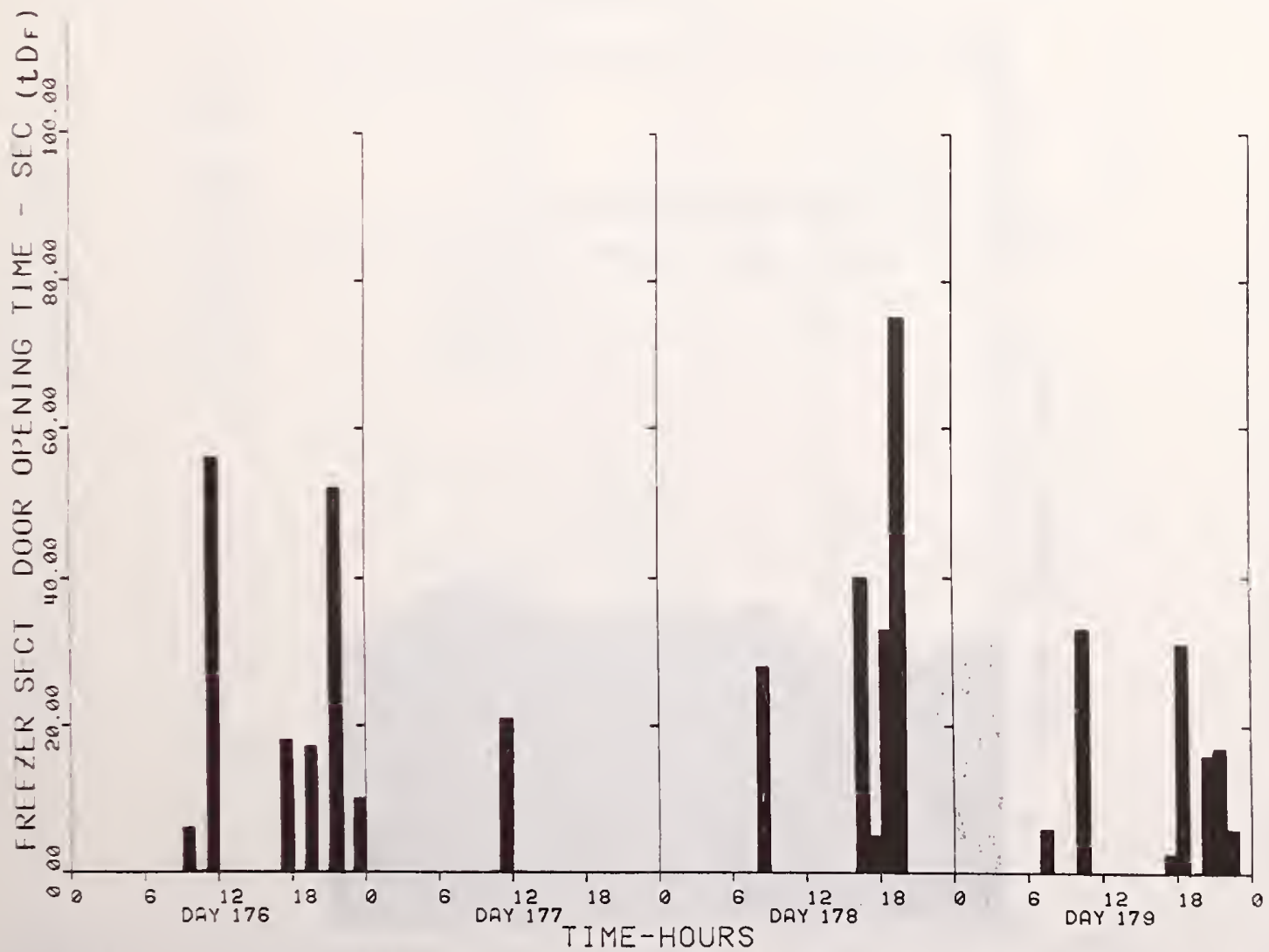

Figure 8 Hourly Freezer Door Opening Time (Townhouse 8) 


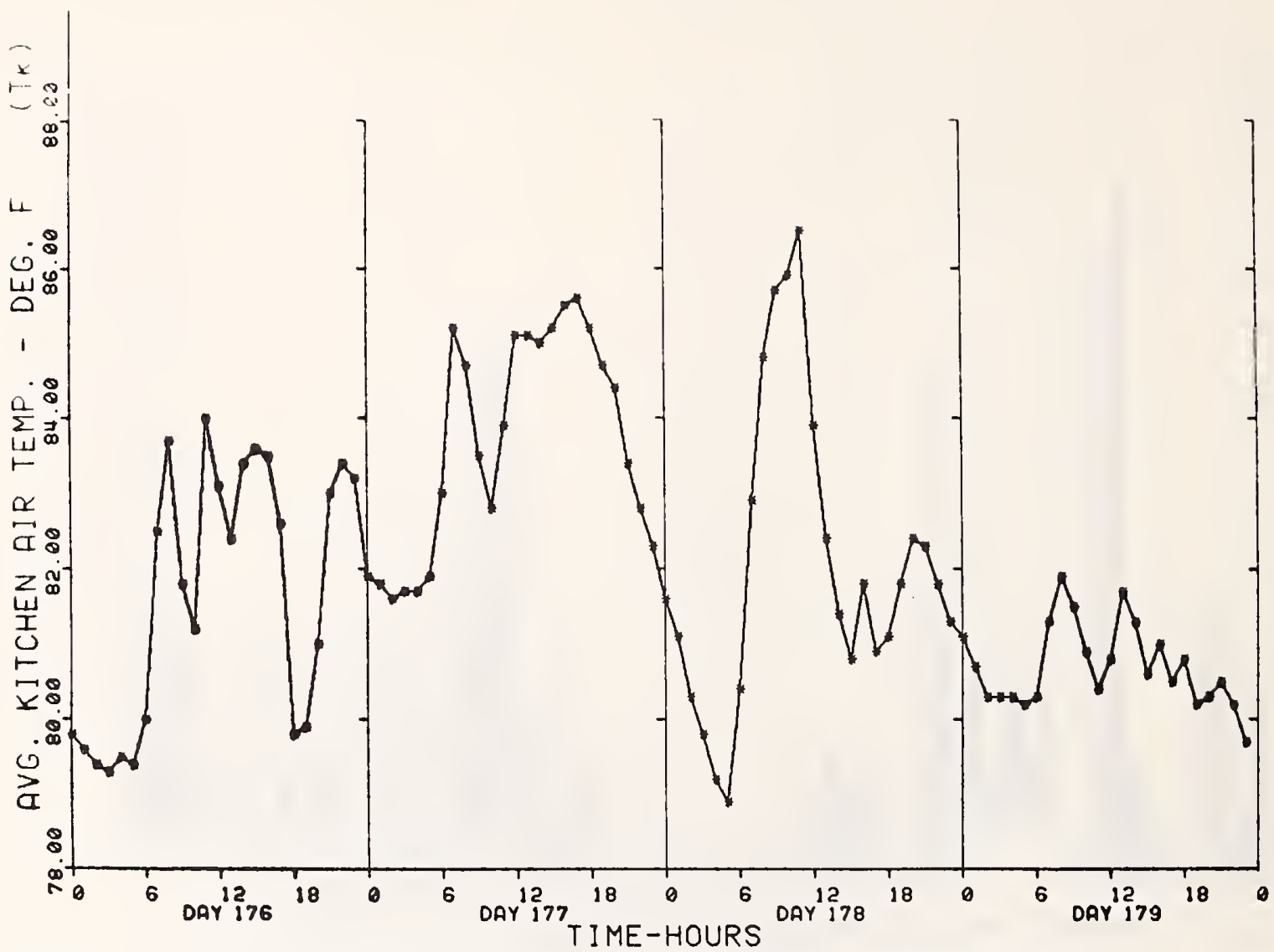

Figure 9 Hourly Average Kitchen Air Temperature (Townhouse 8)

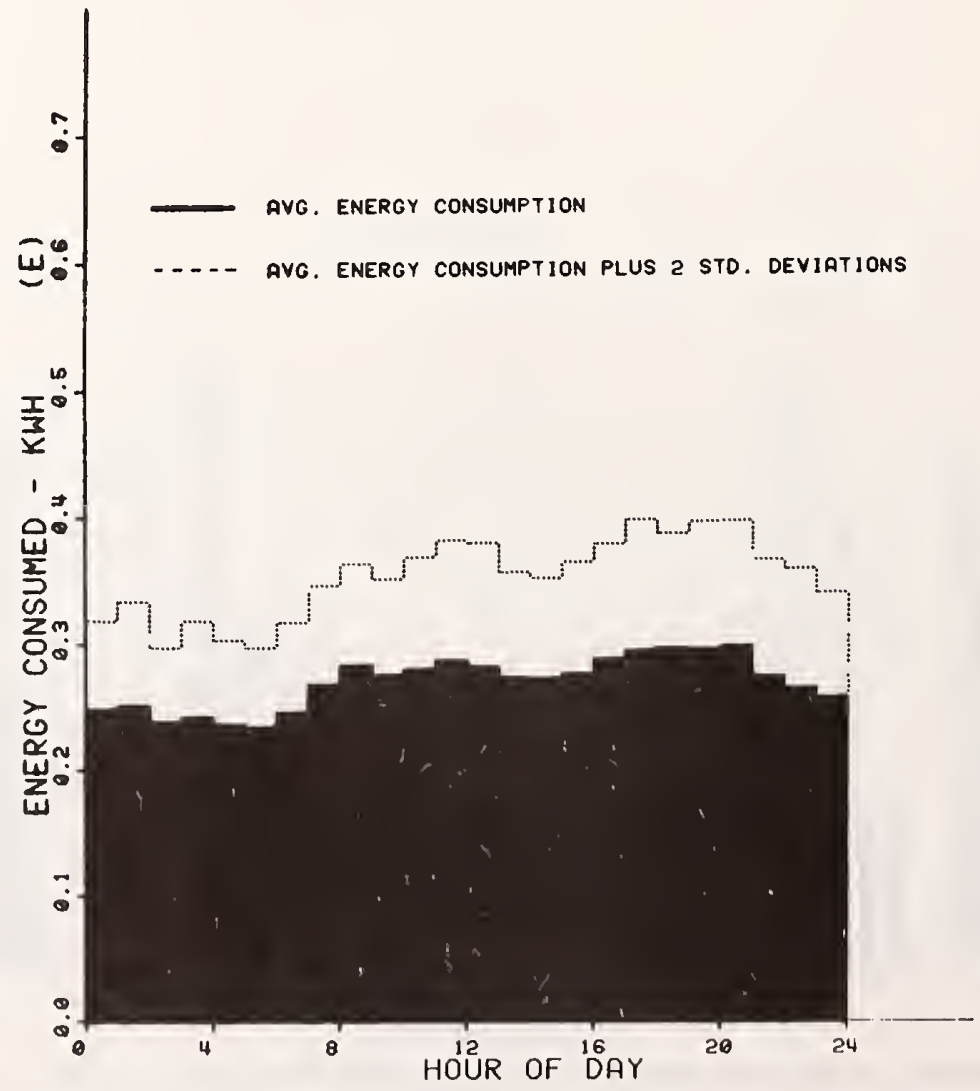

Figure 10 Refrigerator Hourly Profile (Townhouse 8, days 96-180) 


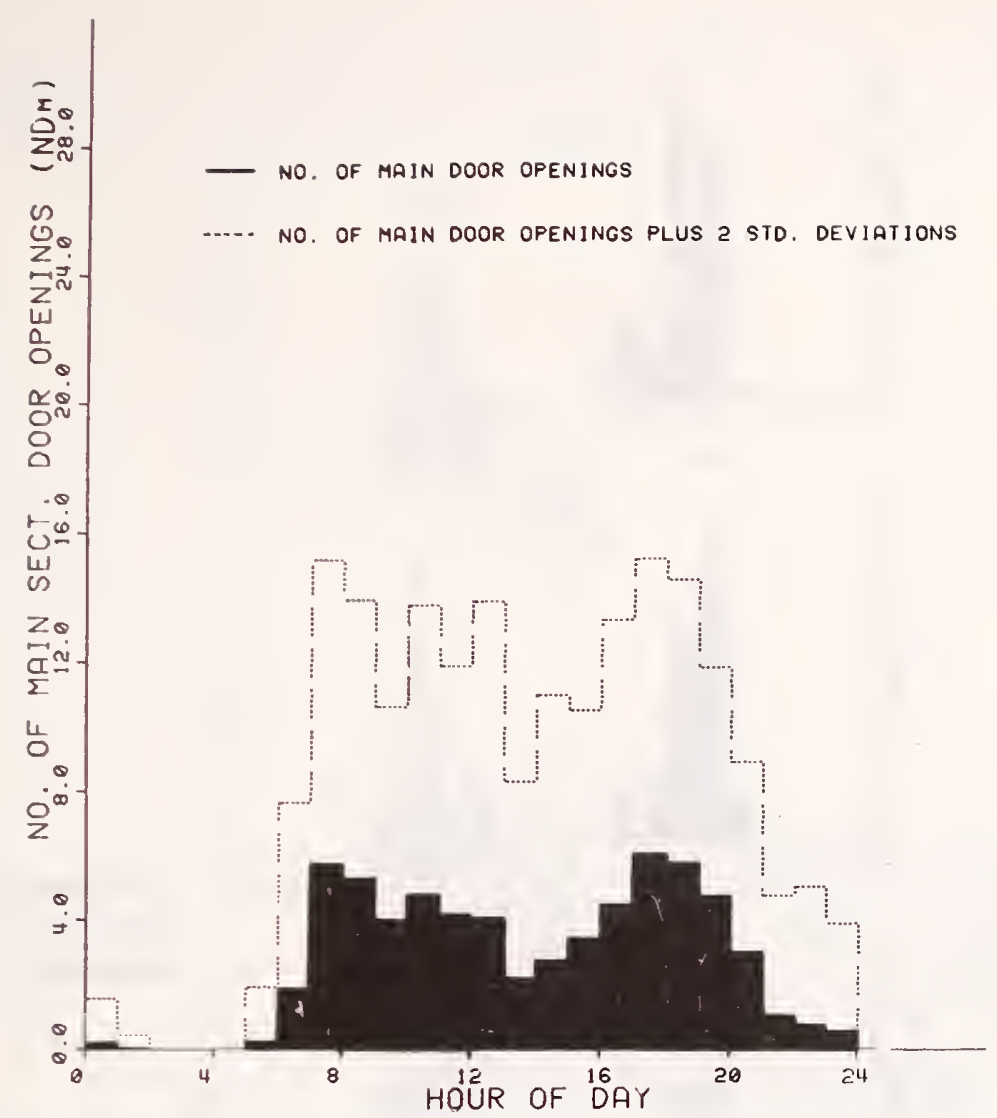

Figure 11 Refrigerator Hourly Profile, Main Section Door Openings (Townhouse 8 , days 96-180)

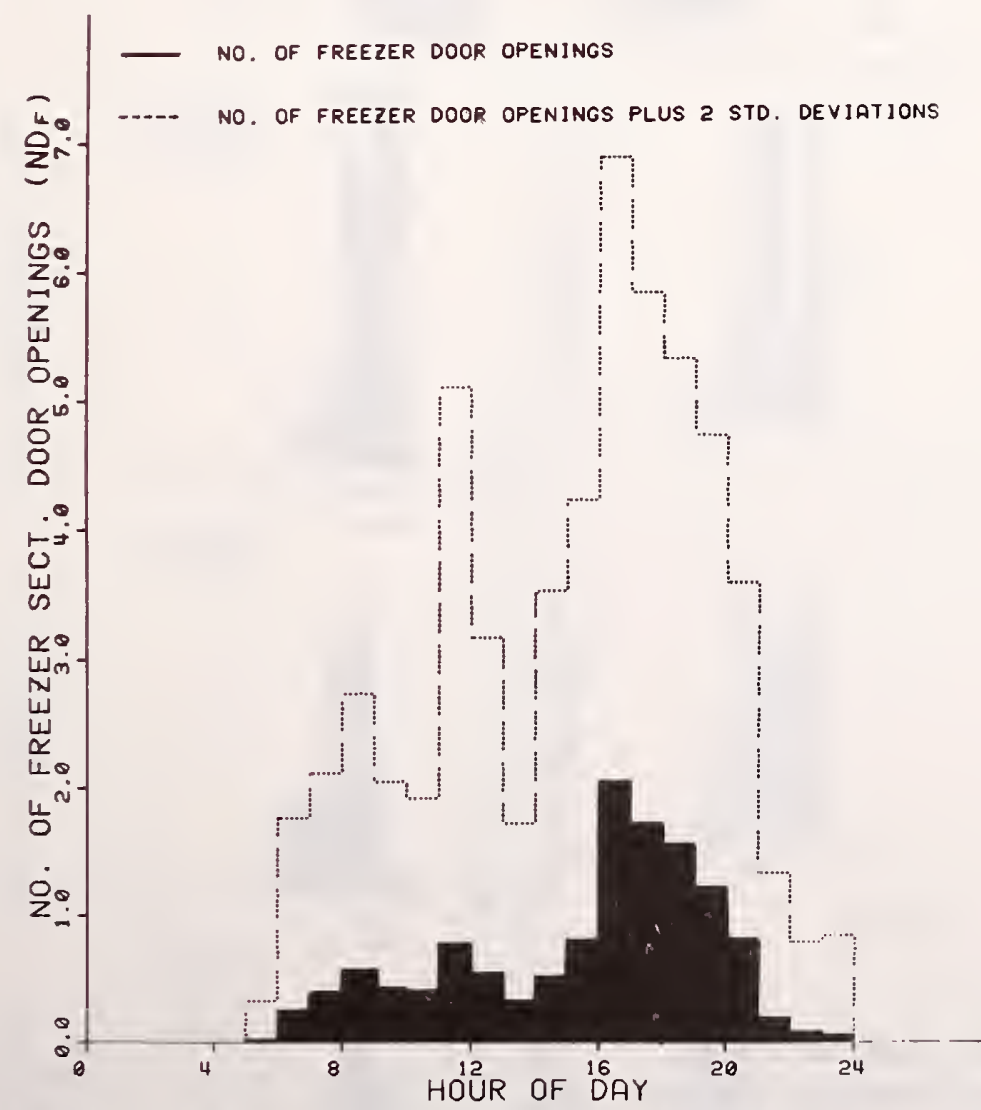

Figure 12 Refrigerator Hourly Profile, Freezer Door Openings (Townhouse 8, days 96-180) 

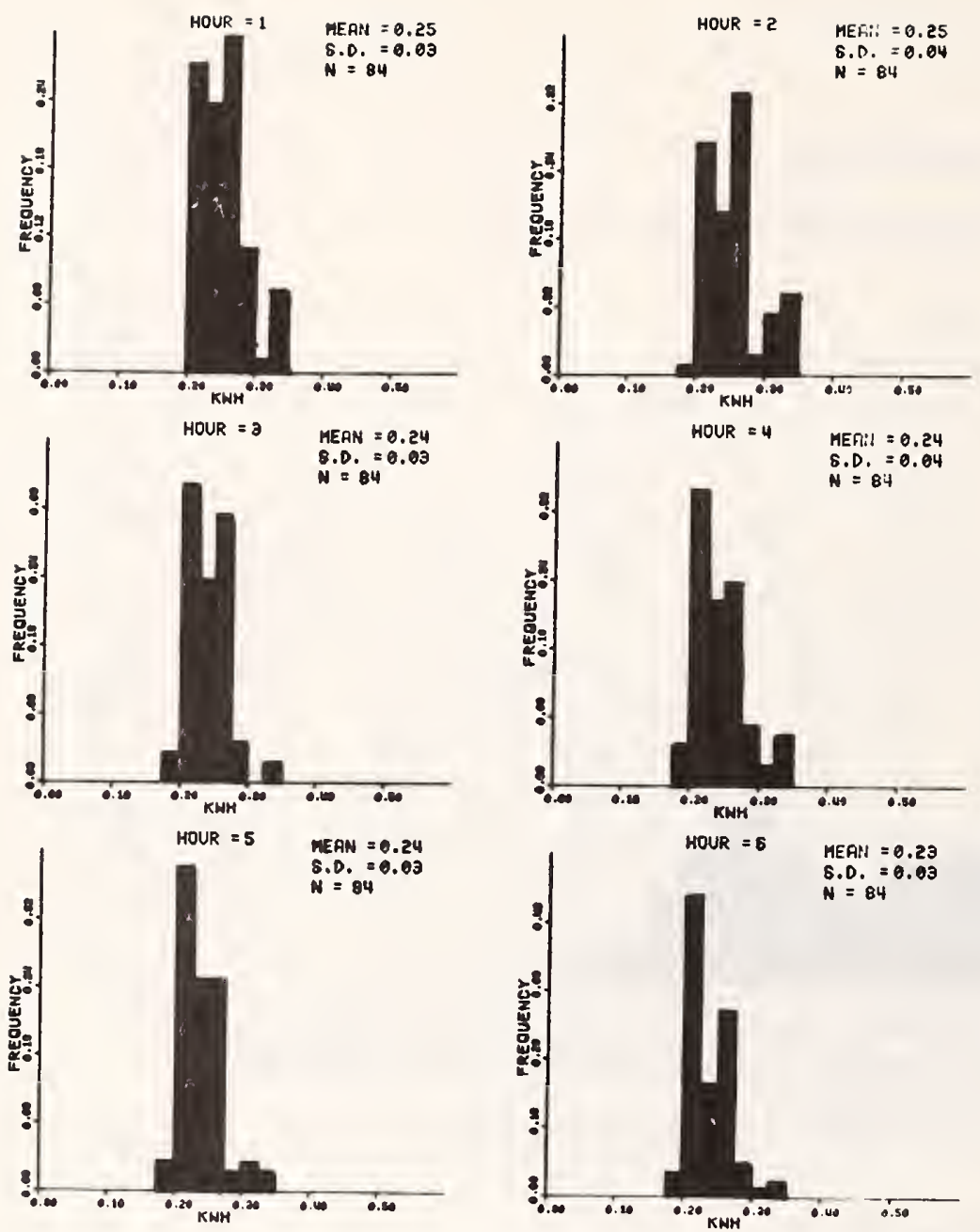

Figure 13 Frequency Distributions, Townhouse 8 Hourly Energy Consumption (hours 1-6)
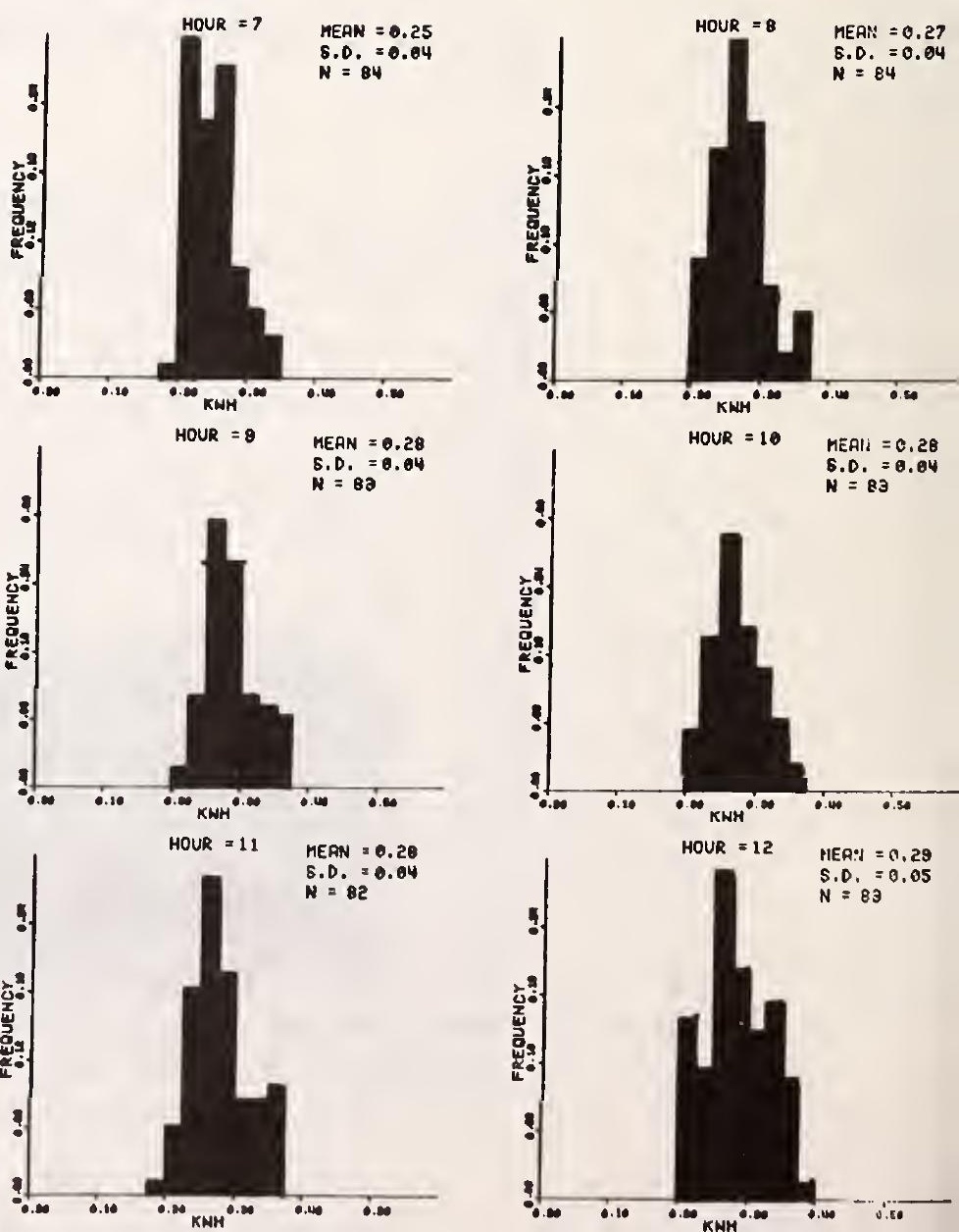

Figure 14 Frequency Distributions, Townhouse 8 Hourly Energy Consumption (hours 7-12)

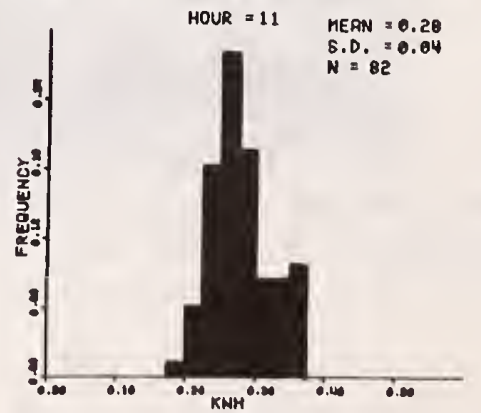



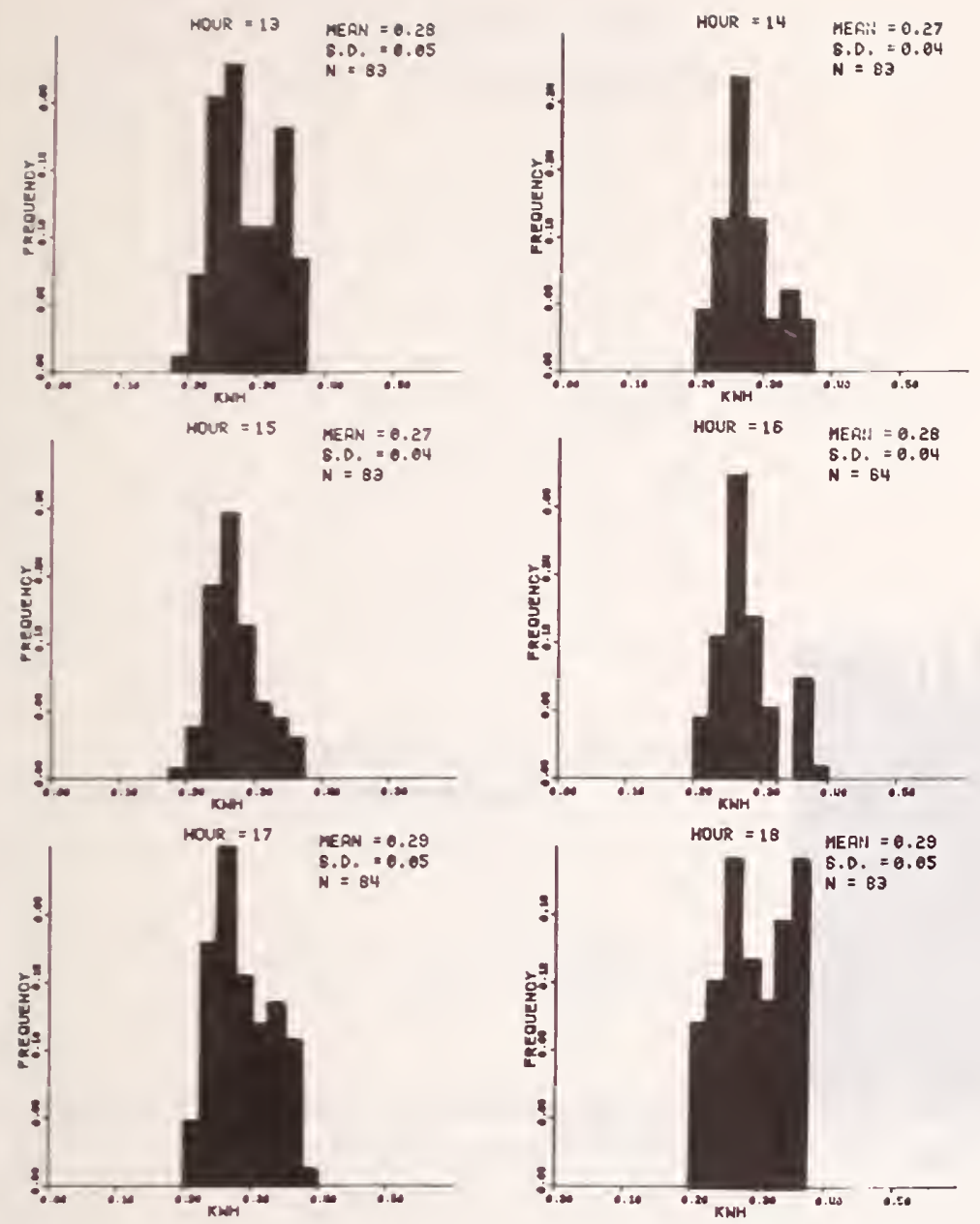

Figure 15 Frequency Distributions, Townhouse 8 Hourly Energy Consumption (hours 13-18)
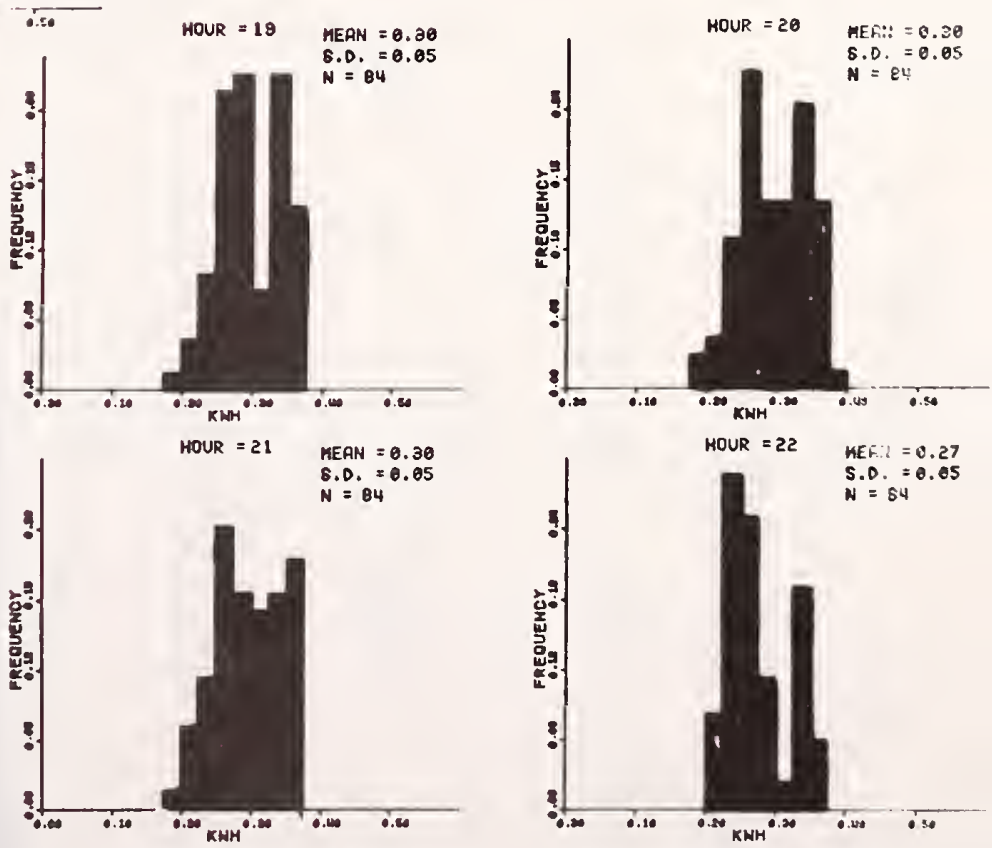

Figure 16 Frequency Distrihutions, Townhouse 8 Hourly Energy Consumption (hours 19-24)
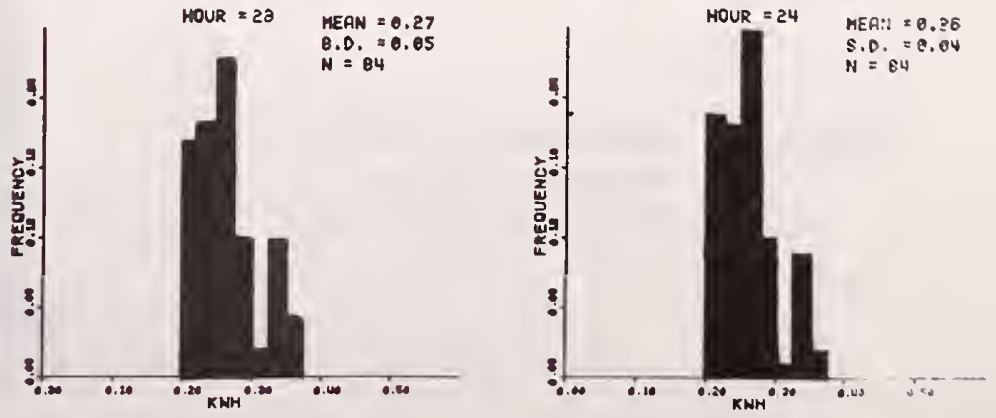


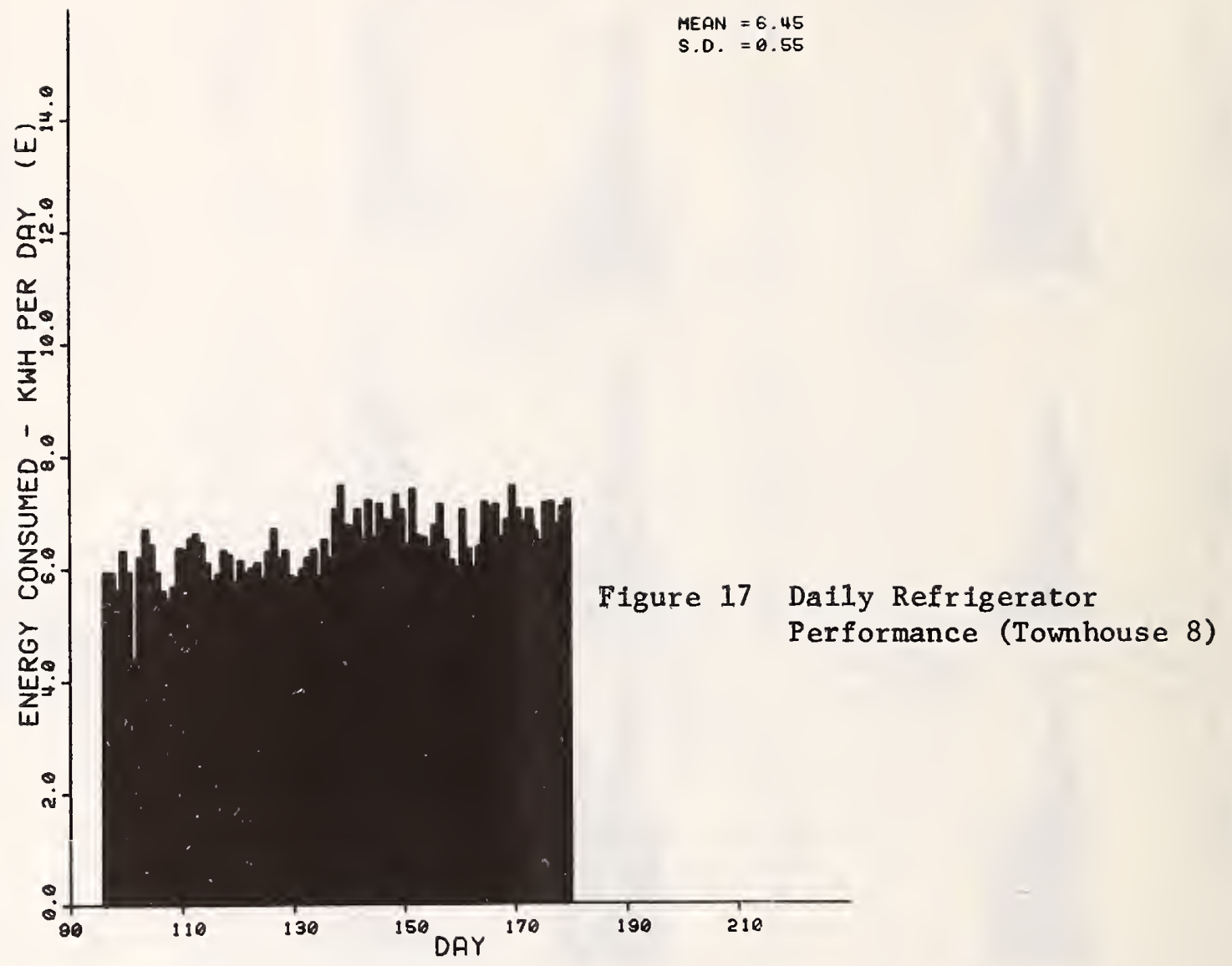

Figure 18 Refrigerator Daily

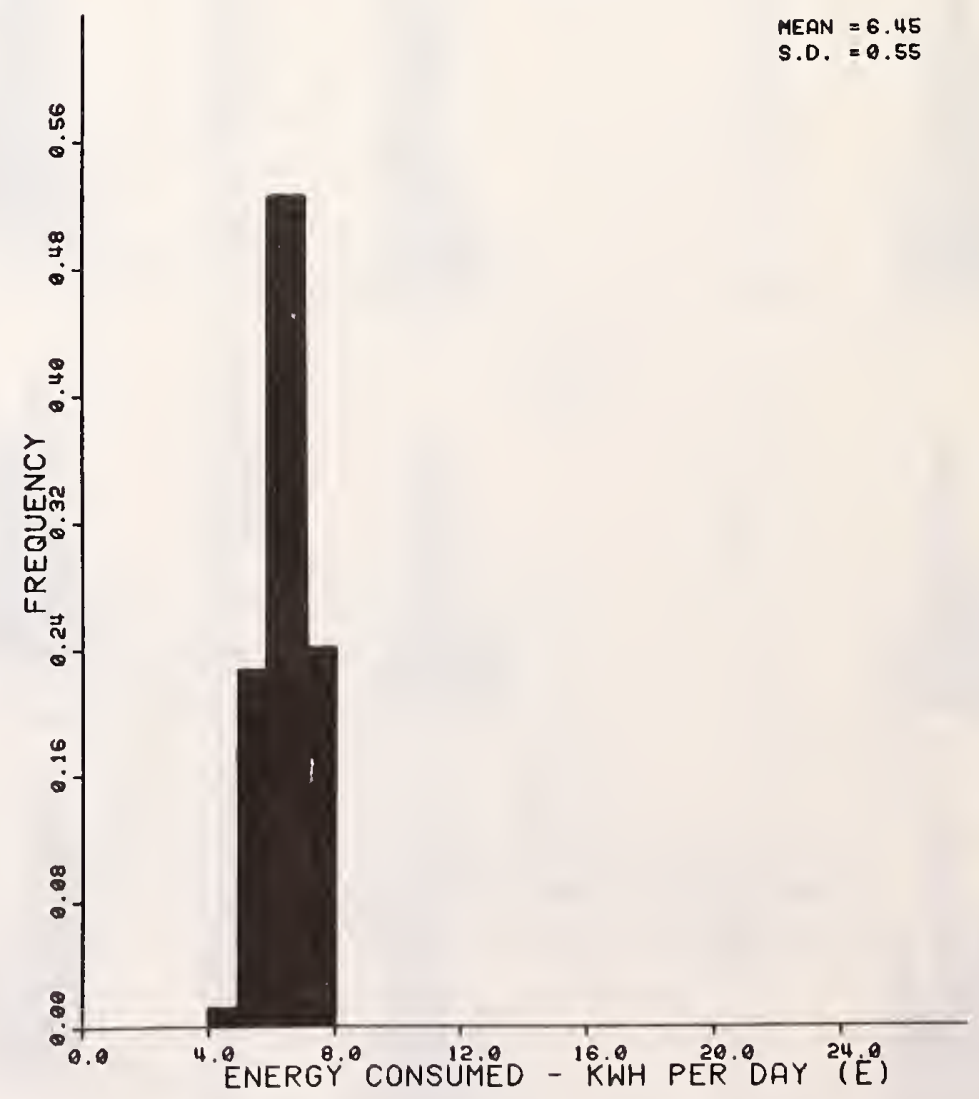




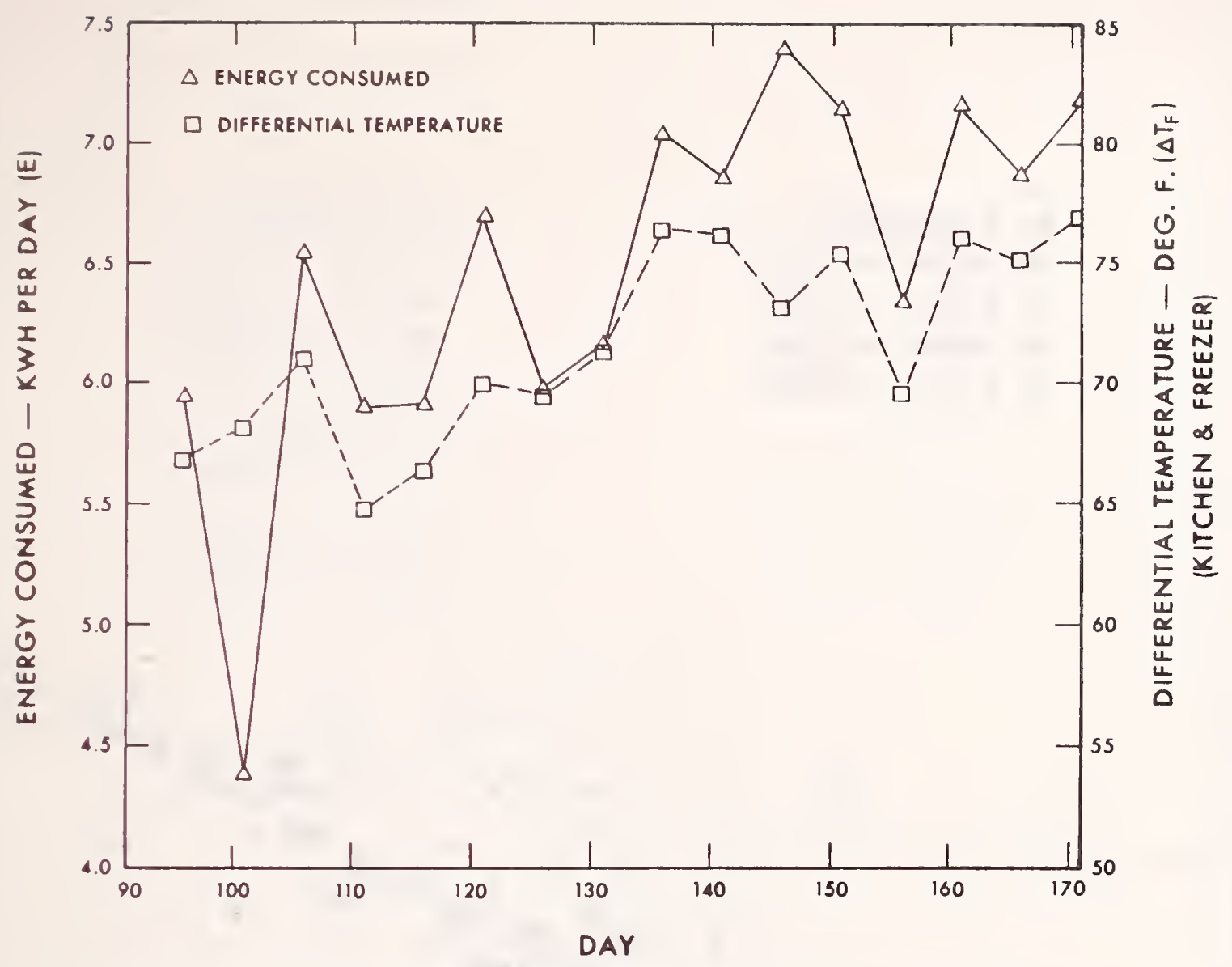

Figure 19 Energy Consumption and Differential Temperature versus Days for Refrigerator (Townhouse 8)

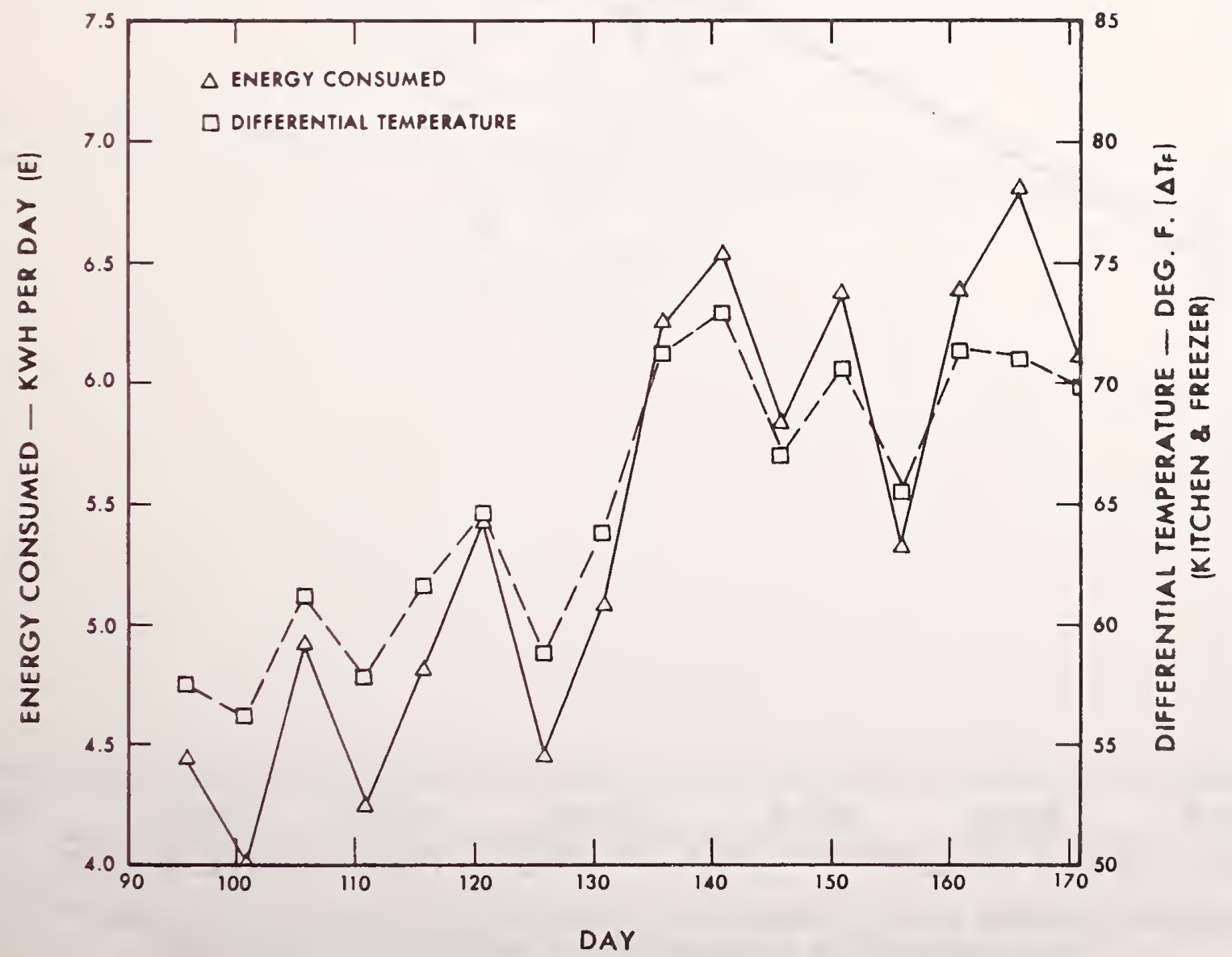

Figure 20 Energy Consumption and Differential Temperature versus Days for Refrigerator (Townhouse 7) 


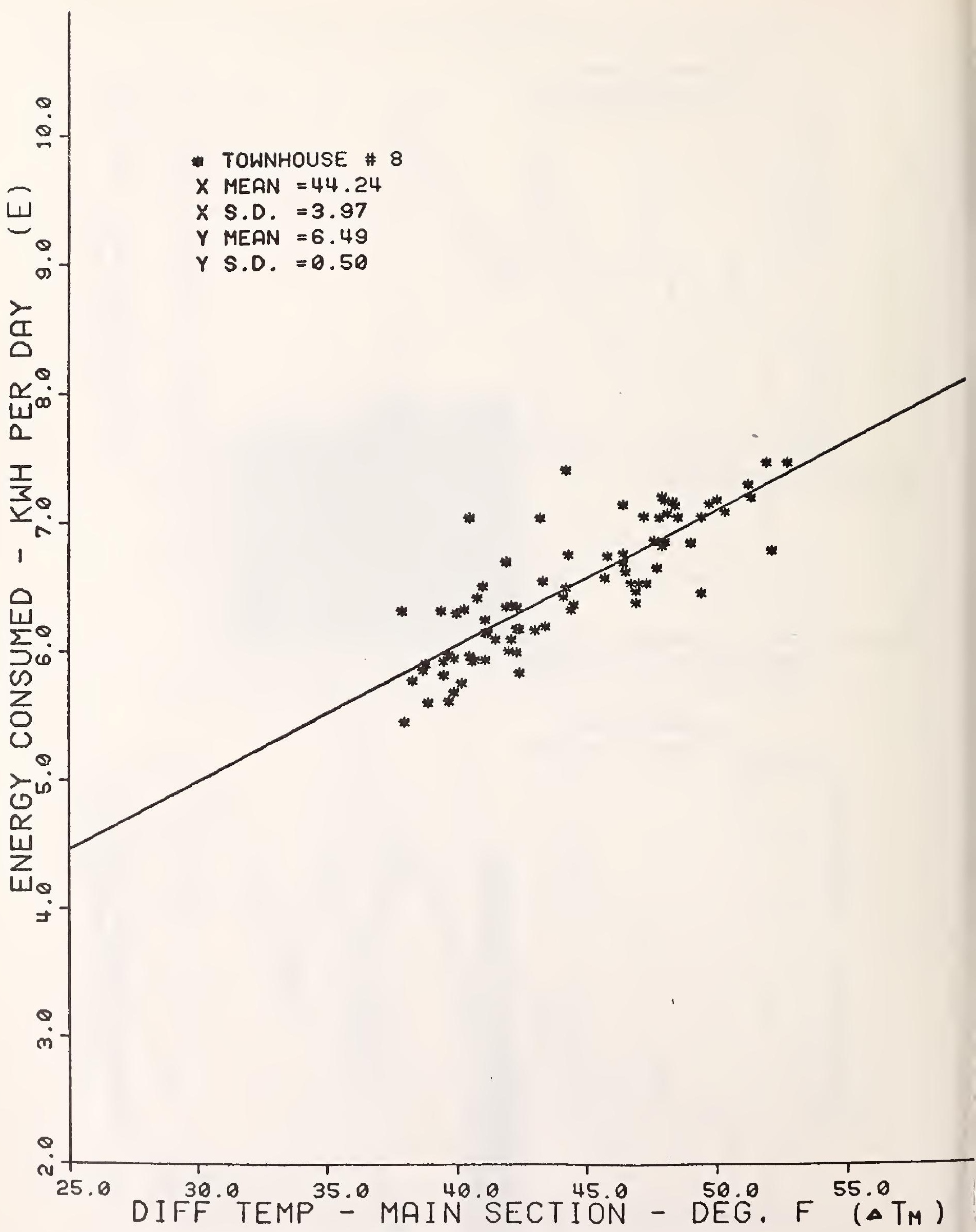

Figure 21 Daily Energy Consumption versus Main Section Differential Temperature for Refrigerator (Townhouse 8, days 96-180) 


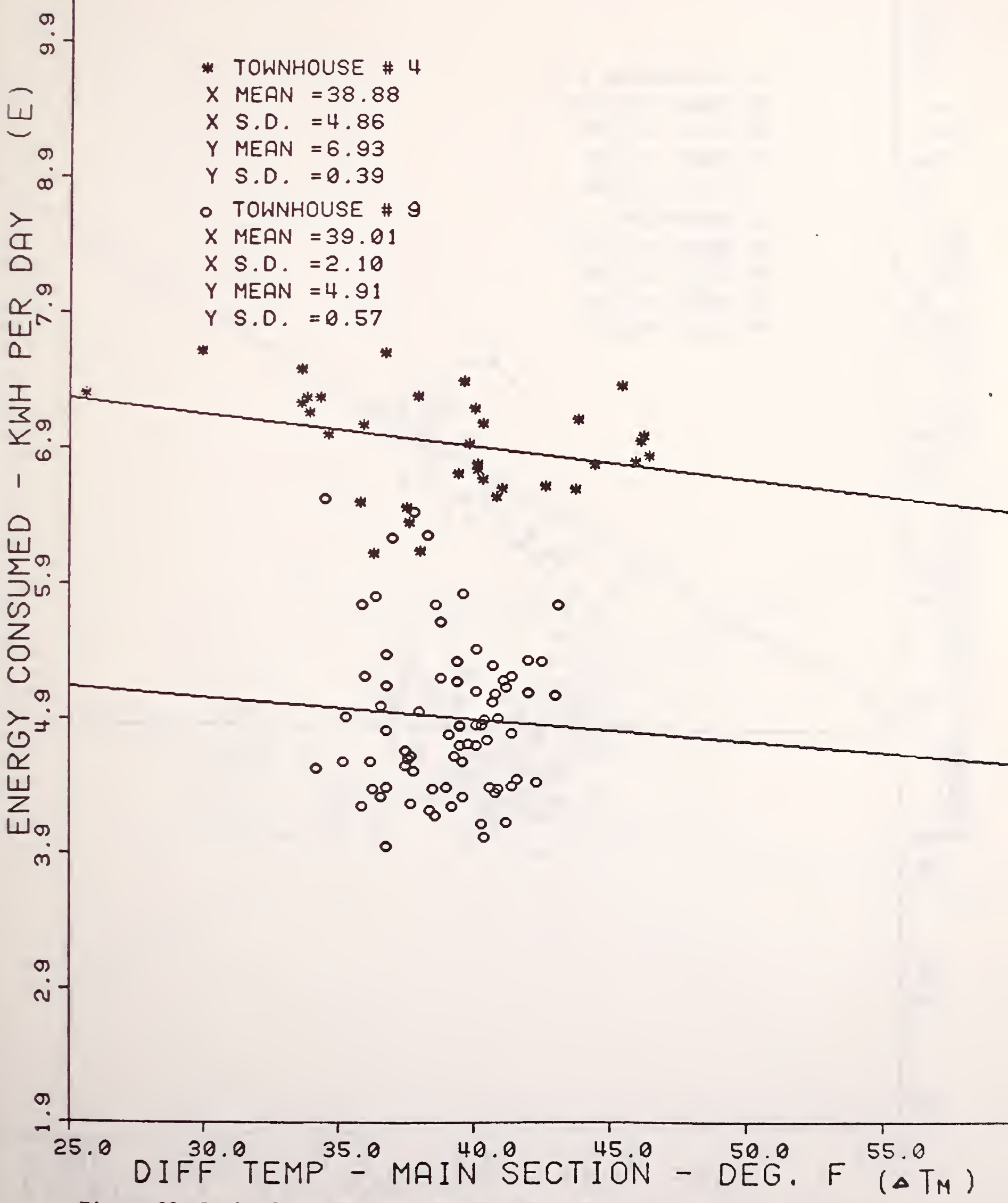

Figure 22 Lack of Correlation Between Refrigerator Energy Consumption and Main Section Differential Temperature (Townhouses 4 and 9 , days 92-174) 


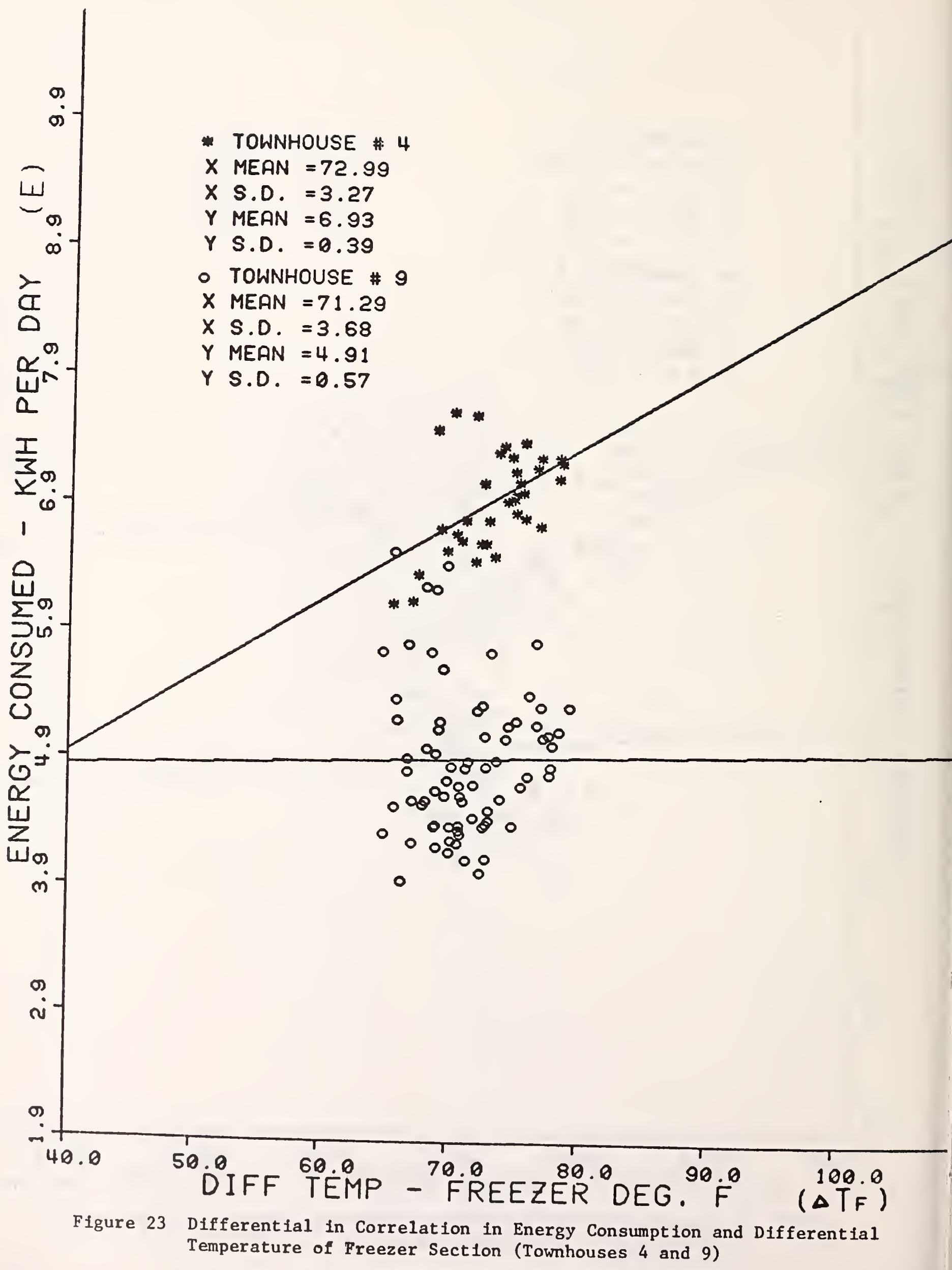




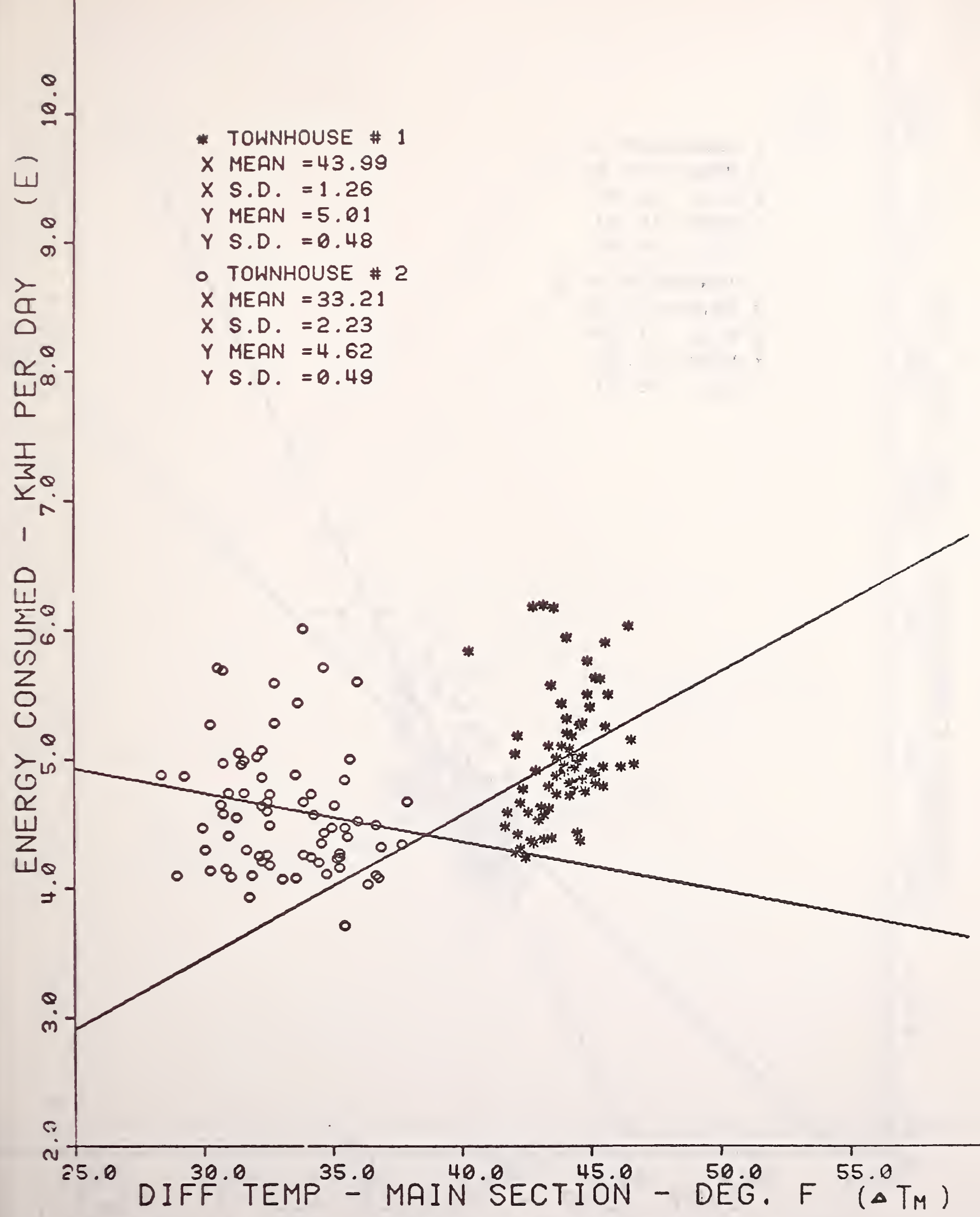

Figure 24 Energy Consumption versus Differentlal Temperature of Main Section for Refrigerator (Townhouses 1 and 2, days 167-249) 


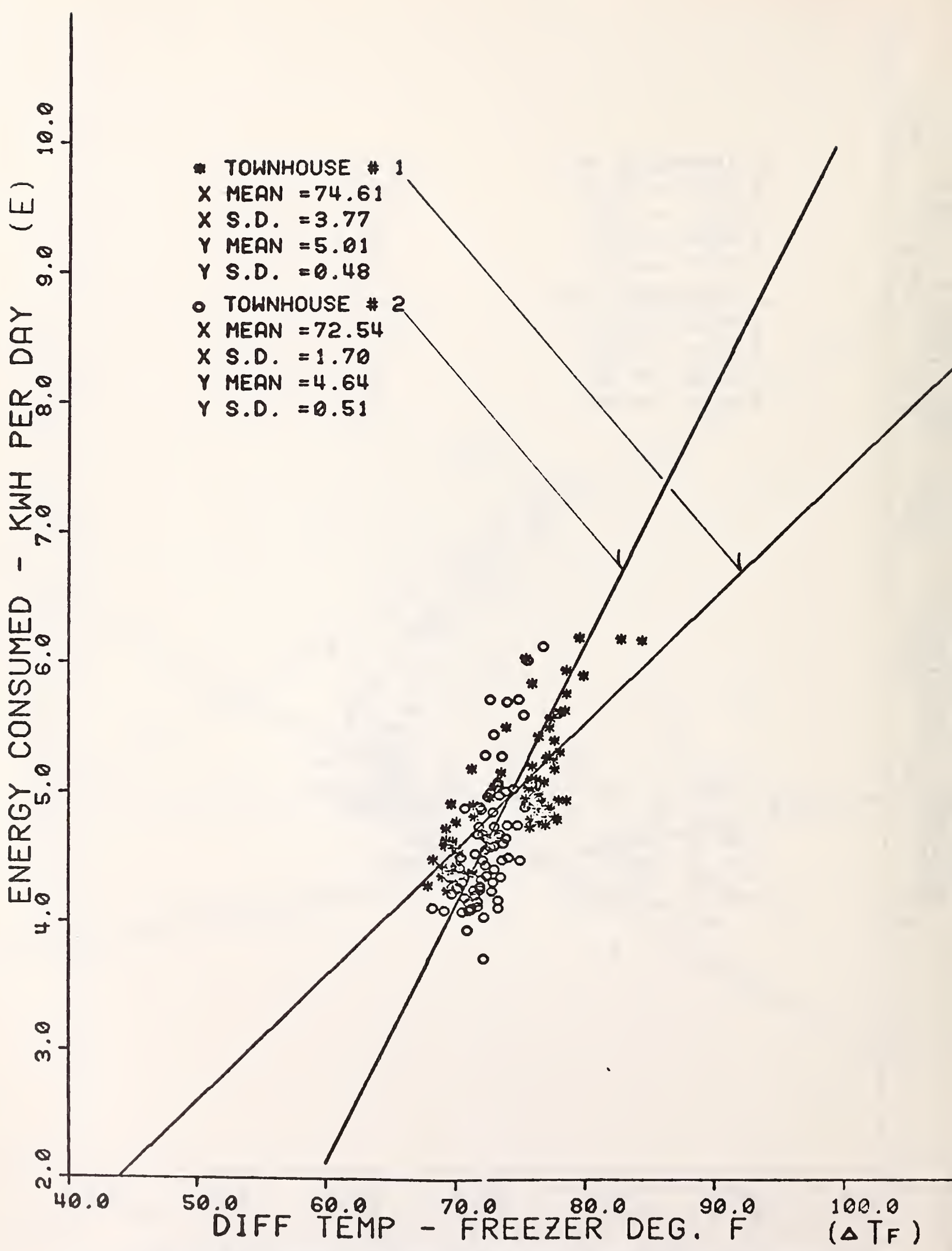

F1gure 25 Energy Consumption versus Differential Temperature of Freezer Section for Refrigerator (Townhouses 1 and 2, days 167-249) 


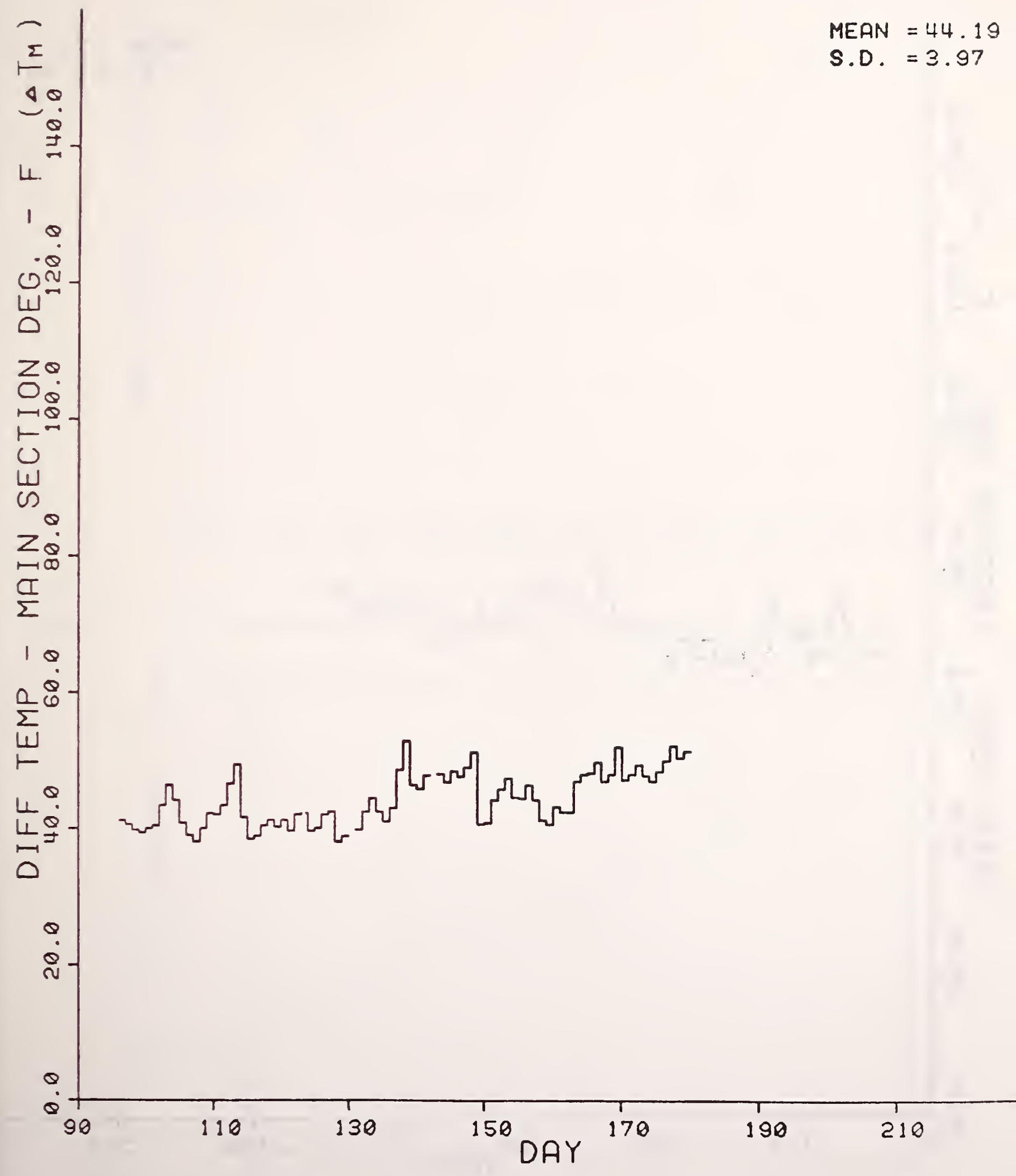

Figure 26 Daily Average Differential Temperature of Main Section versus Days for Refrigerator (Townhouse 8) 


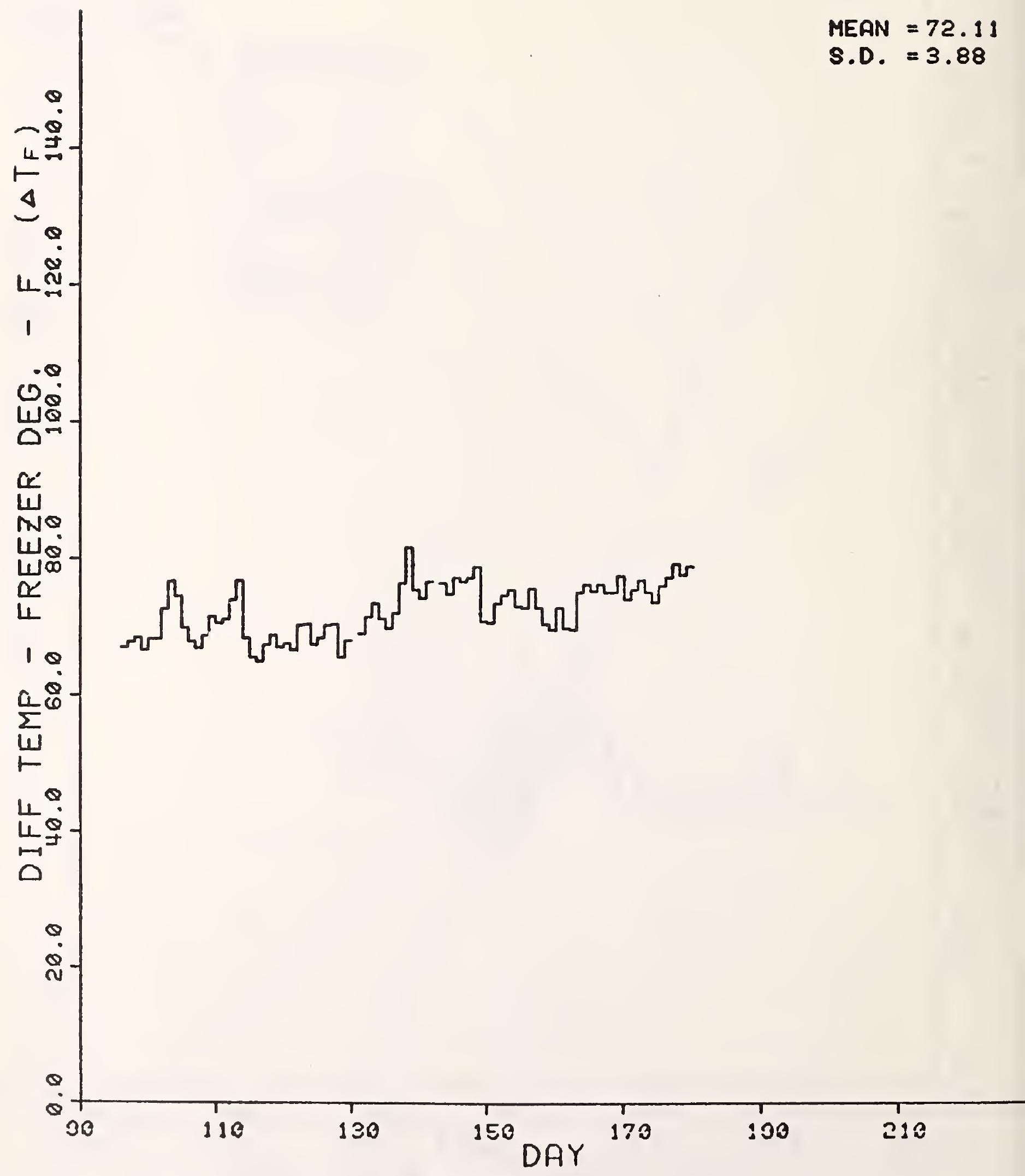

Figure 27 Da1ly Average Differential Temperatures of Freezer Section versus Days (Townhouse 8) 


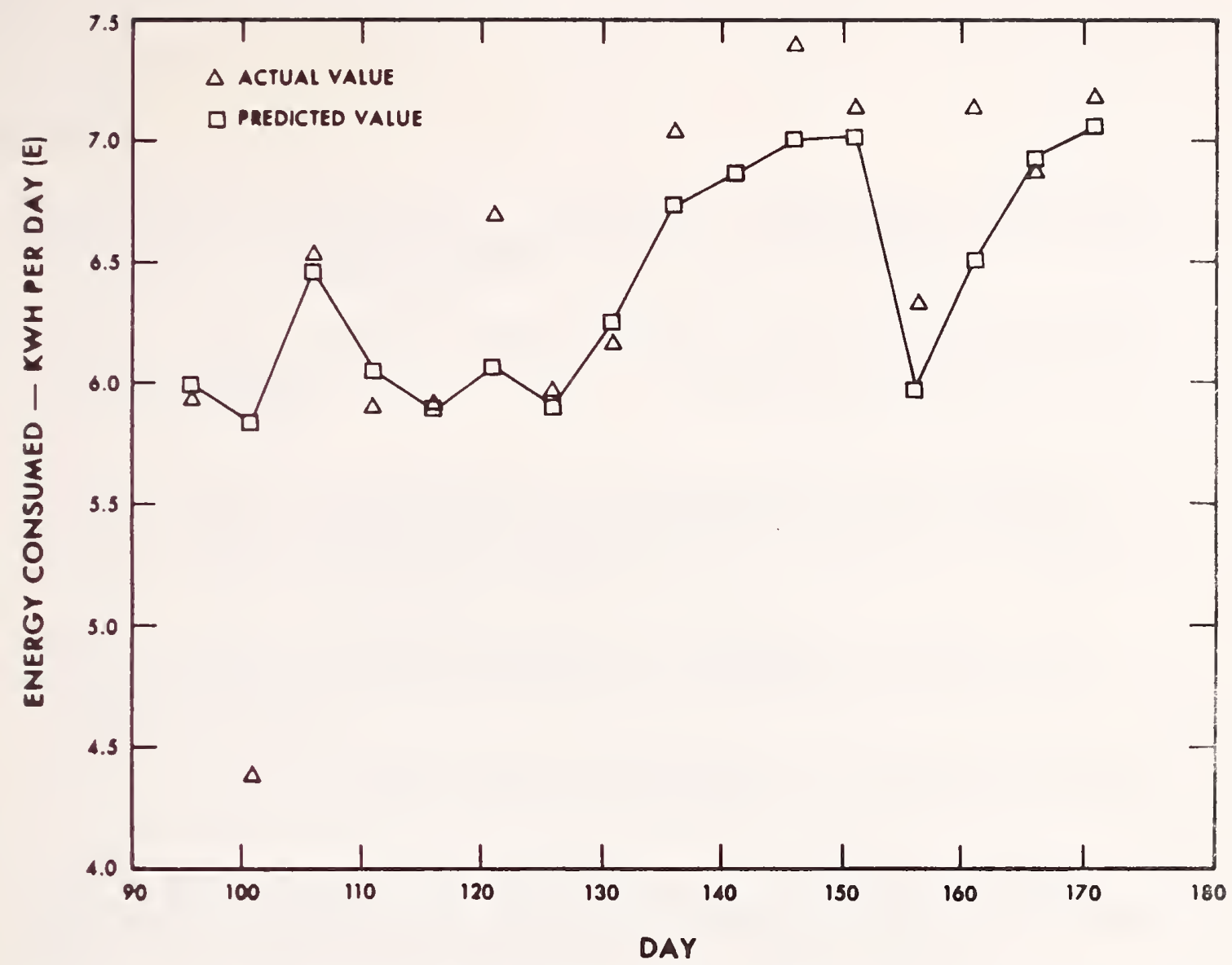

Figure 28 Actual and Predicted Refrigerator Energy Consumption (Townhouse 8)

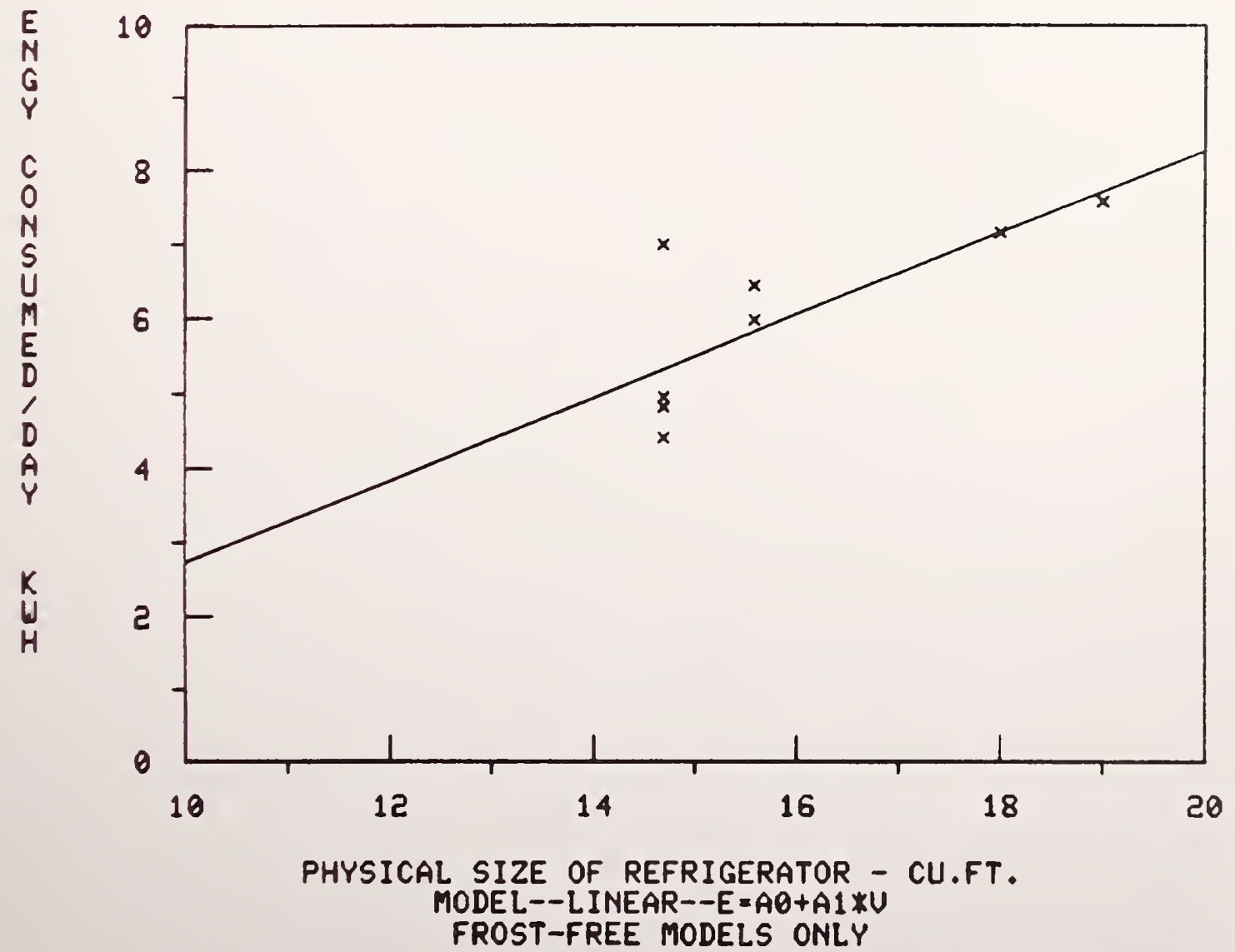

Figure 29 Energy Consumption of Refrigerator vs. Refrigerator Size 



\section{REFERENCES}

1. Grot, R.A. and Socolow, R.H., "Energy Utilization in a Residential Community" in Energy Demand, Conservation and Institutional Problems. ed. Michael Macrakis (Cambridge, Mass., MIT Press 1974).

2. Socolow, R.H., "The Twin Rivers Program on Energy Conservation in Housing: Highlights and Conclusions" Energy and Buildings, Vol. 1, No. 3, April 1978.

3. Association of Home Appliance Manufacturers (AHAM) Standard No. HRF-2-ECFT, Test Procedure to Determine the Freezer Temperature and Energy Consumption of Household Refrigerators, Combination Refrigerator-Freezers and Freezers.

4. American National Standard B 38.1-1970, Methods of Testing for Household Refrigerators, Combination Refrigerator-Freezers, and Household Freezers.

5. Newton, G.C., Jr. "Energy and the Refrigerator" Technology Review, January, 1976.

6. Mulroy, W.J., Grimes, J.W. and Shomaker, B.L. "Effect of Usage Conditions on Household Refrigerator - Freezers and Freezer Energy Consumption" ASHRAE Transactions Vol. 83. Part 1. 1977. 
NBS- II AA (REV. 0.78)

\begin{tabular}{|c|c|c|}
\hline $\begin{array}{l}\text { BIBLIOGRAPHIC OATA } \\
\text { SHEET }\end{array}$ & $\begin{array}{l}\text { 1. PUBLICATION OR REPORT NO. } \\
\text { NBSIR } 79-1781\end{array}$ & 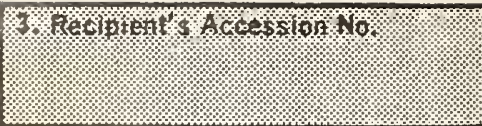 \\
\hline 4. TITLE AND SUBTITLE & $\triangle N C F \quad O F$ RFSTDFNTTAT RFFRTCFPATORS & $\begin{array}{l}\text { 5. Publication Date } \\
\text { July } 1979\end{array}$ \\
\hline \multicolumn{2}{|c|}{$\begin{array}{l}\text { FIELD PERFORMANCE OF RESIDENTIAL REFRIGERATORS } \\
\text { AND COMBINATION REFRIGERATOR-FREEZERS }\end{array}$} & C Performing Organization Code \\
\hline \multicolumn{2}{|l|}{$\begin{array}{l}\text { 7. AUTHOR(S) } \\
\text { Yui-May Chang }\end{array}$} & 8. Performing Organ. Report No. \\
\hline \multicolumn{2}{|c|}{ 9. PERFORMING ORGANIZATION NAME AND ADDRESS } & 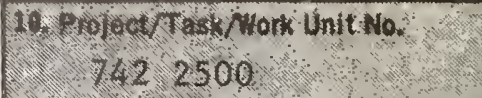 \\
\hline \multicolumn{2}{|c|}{$\begin{array}{l}\text { NATIONAL BUREAU OF STANDARDS } \\
\text { DEPARTMENT OF COMMERCE } \\
\text { WASHINGTON, DC } 20234\end{array}$} & 11. Contract/Grant No. \\
\hline \multicolumn{2}{|c|}{ 12. SPONSORING ORGANIZATION NAME AND COMPLETE ADDRESS (Street, City, state, zIP) } & 13. Type of Report \& Period Covered \\
\hline & & 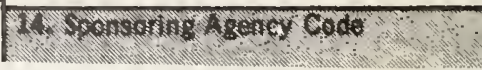 \\
\hline
\end{tabular}

16. ABSTRACT

Evaluation of the performance of household refrigerators and combination refrigeratorfreezers was undertaken in a field experiment to determine the effect of room environment and occupant-usage habits on energy consumption of these appliantes. This report presents the results of such an experiment in ten townhouses at Twin Rivers, N.J. Onedoor manual defrost and two-door frost-free models of various sizes were studied. Energy consumption, kitchen temperature, refrigerator temperature and door openings were measured for each model by data acquisition systems located in the townhouse basements. Both daily and hourly averages and variations about the average for each variable were calculated to determine occupant-usage patterns.

Statistical techniques were utilized to obtain the effect of parameters on energy consumption of these appliances by linear regression of both one- and two-parameter models.

It was found that for a given model the temperature difference between the kitchen and the refrigerator (either main or freezer section) had the most effect on energy consumption, with a lesser, though still important, contribution from the door openings.

In addition, the normalized energy consumption of each model, in different combinations of variables, was calculated from its regression coefficients and the overall average values of parameters from the measurements. The results of these normalized values turned out to be within 5\%. Therefore, their mean values could be considered as the typical energy consumption for each refrigerator or combination, under usage conditions.

The linear relationship among the combination refrigerator-freezers according to their physical sizes indicated an increase of about $0.55 \mathrm{kWh}$ per day for each additional cubic foot increase in volume. Energy conservation by using a manual-defrost refrigerator was predicted at approximately $40 \%$ from the available measurements and other related laboratory test results.

17. Key Words: Combination refrigerator-freezer field data; daily load profiles; energy consumption; field measurements; hourly load profiles; refrigerator field data; usage profiles.

18. AVAILABILITY

For Official Distribution. Do Not Release to NTIS

Order From Sup. of Doc., U.S. Government Printing Office, Wasinington, DC 20402, SD Stock No. SNO03-003-

\begin{tabular}{|l|c|}
$\begin{array}{l}\text { 19. SECURITY CLASS } \\
\text { (THIS REPORT) } \\
\text { UNCLASSIFIED }\end{array}$ & $\begin{array}{c}\text { 21. NO. OF } \\
\text { PRINTED PAGES }\end{array}$ \\
\hline $\begin{array}{l}\text { 20. SECURITY CLASS } \\
\text { (THIS PAGE) }\end{array}$ & $\begin{array}{l}\text { 22. Price } \\
\text { UNCLASSIFIED }\end{array}$ \\
\hline
\end{tabular}

Order From National Technical Information Service (NTIS), Springfield, VA. 22161 

